\title{
Acquisition of German Noun Plurals in Typically Developing Children and Children with Specific Language Impairment
}

\author{
Christina Kauschke, ${ }^{1}$ Anna Kurth, ${ }^{2}$ and Ulrike Domahs ${ }^{1}$ \\ ${ }^{1}$ Philipps-Universität Marburg, Institut für Germanistische Sprachwissenschaft, Wilhelm-Röpke-Straße 6A, \\ 35032 Marburg, Germany \\ 2 Zentrum für Angewandte Psycho- und Patholinguistik, Am Kanal 16-18, 14467 Potsdam, Germany
}

Correspondence should be addressed to Christina Kauschke, kauschke@staff.uni-marburg.de

Received 20 August 2010; Revised 29 November 2010; Accepted 25 January 2011

Academic Editor: Karla K. McGregor

Copyright ( $) 2011$ Christina Kauschke et al. This is an open access article distributed under the Creative Commons Attribution License, which permits unrestricted use, distribution, and reproduction in any medium, provided the original work is properly cited.

The present study investigates the acquisition of plural markers in German children with and without language impairments using an elicitation task. In the first cross-sectional study, 60 monolingual children between three and six years of age were tested. The results show significant improvements starting at the age of five. Plural forms which require a vowel change (umlaut) but no overt suffix were most challenging for all children. With regard to their error patterns, the typically developing children preferably overapplied the suffix -e to monosyllabic stems and added -s to stems ending in a trochee. Though the children made errors in plural markings, the prosodic structures of pluralized nouns were kept legitimate. In the second study, the production of plural markers in eight children with SLI was compared to age-matched and MLU-matched controls. Children with SLI performed at the level of the MLU-matched controls, showing subtle differences with regard to their error patterns, and their preferences in addition and substitution errors: In contrast to their typically developing peers, children with SLI preferred the frequent suffix $-\mathrm{n}$ in their overapplications, suggesting that they strongly rely on frequency-based cues. The findings are discussed from a morphophonological perspective.

\section{Introduction}

The German plural system is a complex inflectional system with a number of idiosyncrasies. A language-learning child has to face a probabilistic system with multiple regularities and subregularities without a clear-cut distinction between regular and irregular forms (see [1]). Laaha and colleagues state that "inflectional systems such as the German noun plural marking are fraught with complexities which prevent their early mastery" [2]. From a morphophonological perspective, certain prosodic constraints guide plural formation, which makes the German plural system an ideal test case to investigate prosodic influences on the acquisition of morphological paradigms.

The purpose of the present study is to gain an insight into the acquisition of the complex German plural system. By investigating plural formation in children of different ages, we aim at establishing a hierarchy of difficulty of the plural markers and to explore error types and overapplication patterns in more detail. In addition, the intricacies of German plural formation might present a specific obstacle for children with language impairments. Therefore, we examine plural formation in language-impaired children and compare their performance with both age-matched and language-matched peers.

1.1. German Plural System. Plural nouns in German are marked by one of the following six suffixes: -n, -en, -e, -s, -er, $\varnothing$ (zero or no marking). Three of the suffixes $(\varnothing$, -e, -er) can also be combined with the fronting of the stem vowel (umlaut), resulting in nine different ways to mark the morphological category pLuRaL. Additionally, number information is also expressed by a change of the definite article (die in all genders in nominative and accusative case, which is homonymous with the feminine singular article, and der in genitive and dative case). An ongoing question 
TABLE 1: Plural forms according to Eisenberg [3] and Wegener [4, 5].

\begin{tabular}{|c|c|c|}
\hline Masculine & Neuter & Feminine \\
\hline \multicolumn{3}{|l|}{ (1a) -e (Schwein-e, "pigs"; Buss-e, "buses") } \\
\hline \multicolumn{3}{|l|}{ (1b) -e + UML (Bäll-e, "balls”) } \\
\hline (1c) $-\varnothing$ (Sessel - $\varnothing$, “armchairs") & & (2a) -en (Tür-en, “doors”) (2b) -n (Nase -n, “noses") \\
\hline \multicolumn{3}{|l|}{ (1d) $-\varnothing+$ UML (Väter - $\varnothing$, “fathers") } \\
\hline \multicolumn{3}{|l|}{ (1c) and (1d) after (pseudosuffixes) } \\
\hline (3a) -en (Held-en, "heroes") (3b) -n (Hase-n, "rabbits") & $\begin{array}{l}\text { (4) -er + UML } \\
\text { (Häus-er, "houses") }\end{array}$ & (5) -e + UM L (Händ-e, "hands") \\
\hline
\end{tabular}

Note that the suffixes -en and -n appear twice in feminine context ((2a) and (2b)) and in masculine contexts ((3a) and (3b), marked forms). The plural form -e plus Umlaut appears in masculine/neuter contexts ((1b), UMLAUT is lexicalized) and in feminine context ((5), here UMLAUT is obligatory).

is how much regularity or irregularity is inherent in the German plural system. The application of the suffixes to specific nouns is not arbitrary, but depends in part on gender as well as phonological and prosodic features of the noun stem. A recent classification of the German plural suffixes with respect to gender distinctions proposed by Eisenberg [3] and Wegener $[4,5]$ is depicted in Table 1.

Table 1 shows that the majority of the suffixes are linked to certain gender forms. More than $70 \%$ of masculine and neuter nouns take -e as their regular suffix (type 1), combined with umlaut (1b) or not (1a). After the so-called pseudosuffixes (type $(1 \mathrm{c})+(\mathrm{d})$, words ending with -en, -el, and -er, which resemble German suffixes, but are part of the noun stem), there is no overt marking with a suffix, but sometimes the umlaut is required (1d). $96 \%$ of feminine nouns are regularly marked by $-n$ or -en (type 2 ). Since $-n$ is used after nouns ending in a schwa syllable, $-n$ and -en are often regarded as allomorphs. While types 1 and 2 are considered to be typical forms, types 3 and 5 are described as marked forms $[3,5]$ because of their exceptional combination of suffix and gender: the regular suffix -(e)n for feminine nouns is applied to masculine nouns (type 3), or the regular suffix -e for masculine and neuter nouns is added to feminine nouns (type 5). The -er plural (type 4 ) is mostly restricted to neuter nouns and attaches to a lexicalized class of monosyllabic nouns only [6]. Due to its nonproductivity (cf. [2]) and low frequency this suffix is considered to be untypical. The -s plural (type 6) is assumed to be "special" in the literature, since it is relatively free in its phonological distribution. The suffix occurs with nouns of any gender and is used in the context of noncanonical or untypical nouns such as names, foreign words, or short forms. Thus, -s is systematically different from all other suffixes [6]. The -s plural is sometimes considered as the default (e.g., [7-10]. However, the -s plural is infrequent and applies to only $4 \%$ of German nouns $(2,6 \%,[11])$. The use of a vowel alternation called umlaut (i.e., the fronting of back vowels and raising/fronting of the low vowel [a]) is governed by a phonological rule under specific morphological conditions. Umlaut is obligatory in some cases (types 4 and 5), but not allowed in others (types $2,3,6$ ). In addition, there are contexts where umlaut is required for some of the nouns, but not for other nouns (see type 1). In the pure umlaut cases, the occurrence of umlaut is lexicalized, that is, synchronically the occurrence of umlaut cannot be predicted. With respect to frequency of the German plural suffixes, Bartke [7, 12] reviewed frequency analyses of different German corpora for adult and child-directed speech and posited the sequence of decreasing frequency: - (e)n $>-e>-\varnothing>-e r>-s$.

There are different degrees of iconicity inherent in German plural forms. The principle of iconicity states that a morphosemantically marked category, compared to an unmarked category, is expressed preferentially by a longer form [13]. With respect to plural formation, "more referents of a kind" correspond to "more phonological structure." Furthermore, the optimal shape of an affix is one syllable. German noun plurals are formed (i) through addition of a syllable (syllabic -e, -(e)n or -er), (ii) through addition of the nonsyllabic consonant -s, (iii) modification without any addition of phonological material (pure umlaut), or (iv) no overt marking. Obviously, there is a decreasing degree of iconicity in these ways of plural formation.

According to Wiese [14], a prosodic constraint requires a plural form to end in an unstressed syllable with either -e (schwa) or a syllabic consonant [14]. In consequence, German noun plurals are mostly disyllabic (e.g., TischTische, "tables"); rare exceptions are monosyllabic nouns with the suffix -s (e.g., Park-Parks, "parks"). Wiese [6] suggests that the ending -e (final schwa) in plural nouns of Standard German is not, as generally assumed, a "real" inflectional suffix but a minimal (epenthetic) vowel added to singular nouns in order to mark the function PLURAL by simply achieving the optimal prosodic shape of plural forms, that is a bisyllabic trochee. A qualitative distinction between -e and the other plural suffixes is supported by the observation that, in contrast to the other suffixes, -e is omitted in many dialects of Standard German [6]. Plural forms without overt marking or pure umlauts (see type (1c) $+(1 \mathrm{~d})$, case (iii) are already prosodically well formed, though violating the iconic principle. The plural system is, therefore, a proper case to investigate the sensitivity to prosodic constraints on morphological processing in language acquisition. Previous studies have rarely addressed morphophonological aspects of pluralacquisition. 


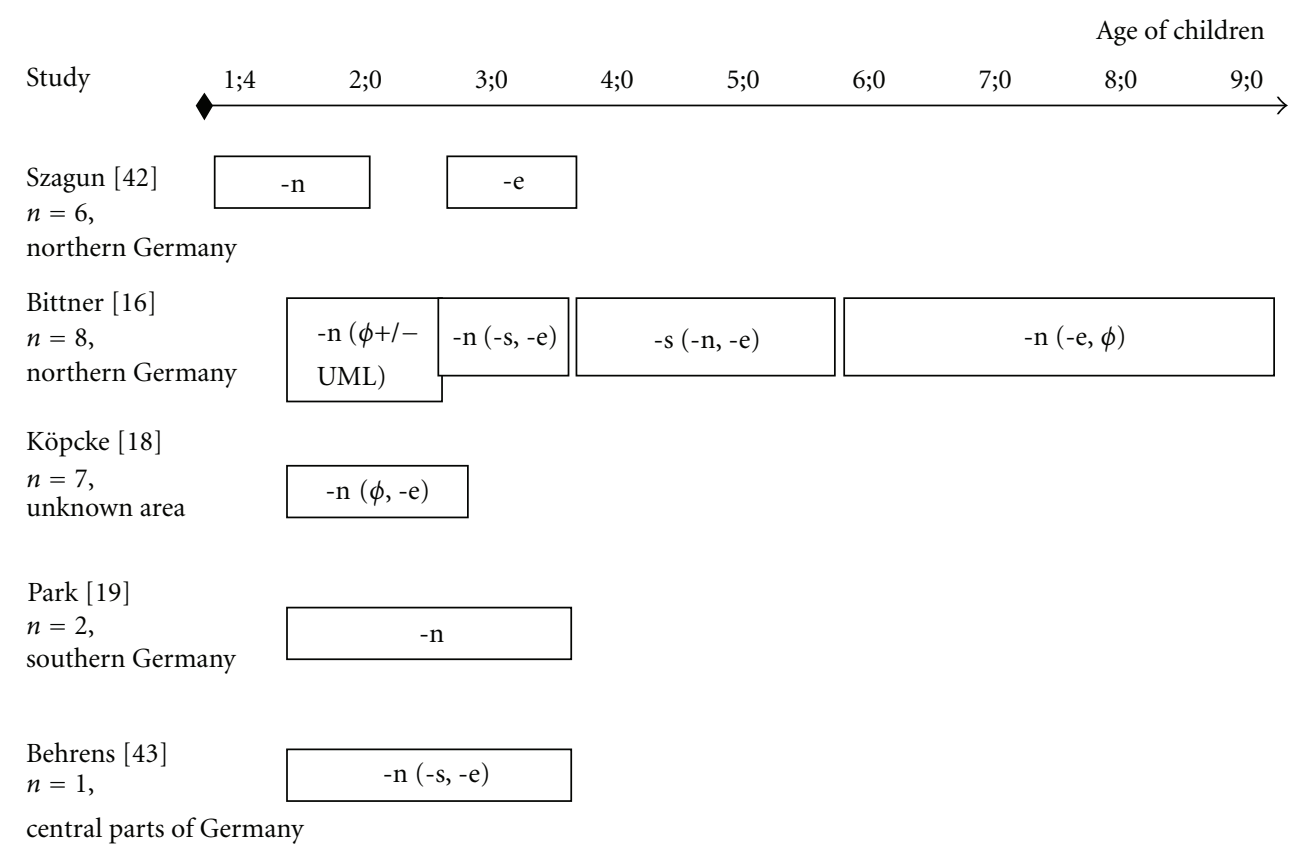

FIGURE 1: overapplications in typically developing children: spontaneous speech studies.

1.2. Acquisition of Noun Plurals in German. Empirical findings on the acquisition of noun plurals are necessarily language-specific, as they depend on the complexity of the inflectional system of a given language. Since most of the empirical studies have investigated the English plural system so far, no simple generalizations can be drawn for morphologically rich languages. As far as plural acquisition in German is concerned, results seem to depend on the methods used. For example, more errors are produced in elicitation tasks compared to spontaneous speech (cf. $[8,9]$ ).

Studies investigating spontaneous speech indicate an early start of plural marking. Szagun [15] examined plural formation in six children between $1 ; 4$ and $3 ; 8$. According to this study, some children already use nouns marked for plural at age $1 ; 4$ to $1 ; 8$. It is likely that these early plurals are holistically memorized forms, rather than outputs of productive morphological processes. The plural suffixes are acquired with different rates. For example, in Szagun's [15] study, -n plurals display a very rapid growth, followed by -e, $-\varnothing$ and -e, plus umlaut, whereas -s and the other umlaut forms have slower growth rates. Bittner [16] conducted a longitudinal study with eight typically developing children from the age of $2 ; 0$ up to $9 ; 11$. She found that the -en plural is acquired first, followed by -s and finally -e. Similar results were obtained by Gawlitzek-Maiwald [17], Köpcke [18], and Park [19]. Laaha et al. [2], in an elicitation task with children aged 2;6 to 6;0, reported that the highest correctness scores were obtained for -e plurals, followed by -e + umlaut, -er + umlaut, $-s$ and -(e)n, with the lowest score for pure umlaut. In contrast to previous findings, their study did not confirm that $-(\mathrm{e}) \mathrm{n}$ is acquired prior to -e. Thus, the developmental sequence of the acquisition of plural markers in German is still unclear.
Despite the early onset of plural marking, there is a long period of instability, since error rates are relatively high throughout the preschool age (up to $16 \%$ according to [15]). Various error types have been observed. Especially in the early stages of language acquisition, children frequently omit plural markers and use singular word forms instead. Overregularizations occur when children regularize irregular forms. Such forms may indicate the abstraction of a rule and are, therefore, considered as the "developmental hallmark of the generalization stage" [20]. Since there is no clearcut distinction between regular and irregular noun plurals in German, the use of the term "overapplication" seems to be more appropriate. Empirical findings from German show that there is no single German suffix which would be applied by default in spontaneous speech and/or elicitations tasks. Figures 1 and 2 summarize the main results on overapplication patterns in different age ranges from studies investigating plural formation in German children. For spontaneous speech, studies converge in the finding that $\mathrm{n}$ is used as the dominant suffix for overapplications until age 3 (see Figure 1). The choice of $-n$ in the early stages of language acquisition may be due to the high frequency and productivity of this suffix $[2,12]$. Overapplication patterns in elicitation studies differ from those observed in spontaneous speech (see Figure 2): Laaha et al. [2] as well as SchanerWolles [21] and Mugdan [11] found that -e was the most frequent plural marker used for overapplications, followed by -n, -s and -e + umlaut. MacWhinney [22] observed that overapplications with -e are most frequently followed by -s instead of -n. Spreng [23] and Niedeggen-Bartke [12] found that $-\mathrm{s}$ was most frequently used in overapplications, followed by -e and $-n$ (only [12]). The frequent use of -e may be caused by prosodic requirements. For children who 


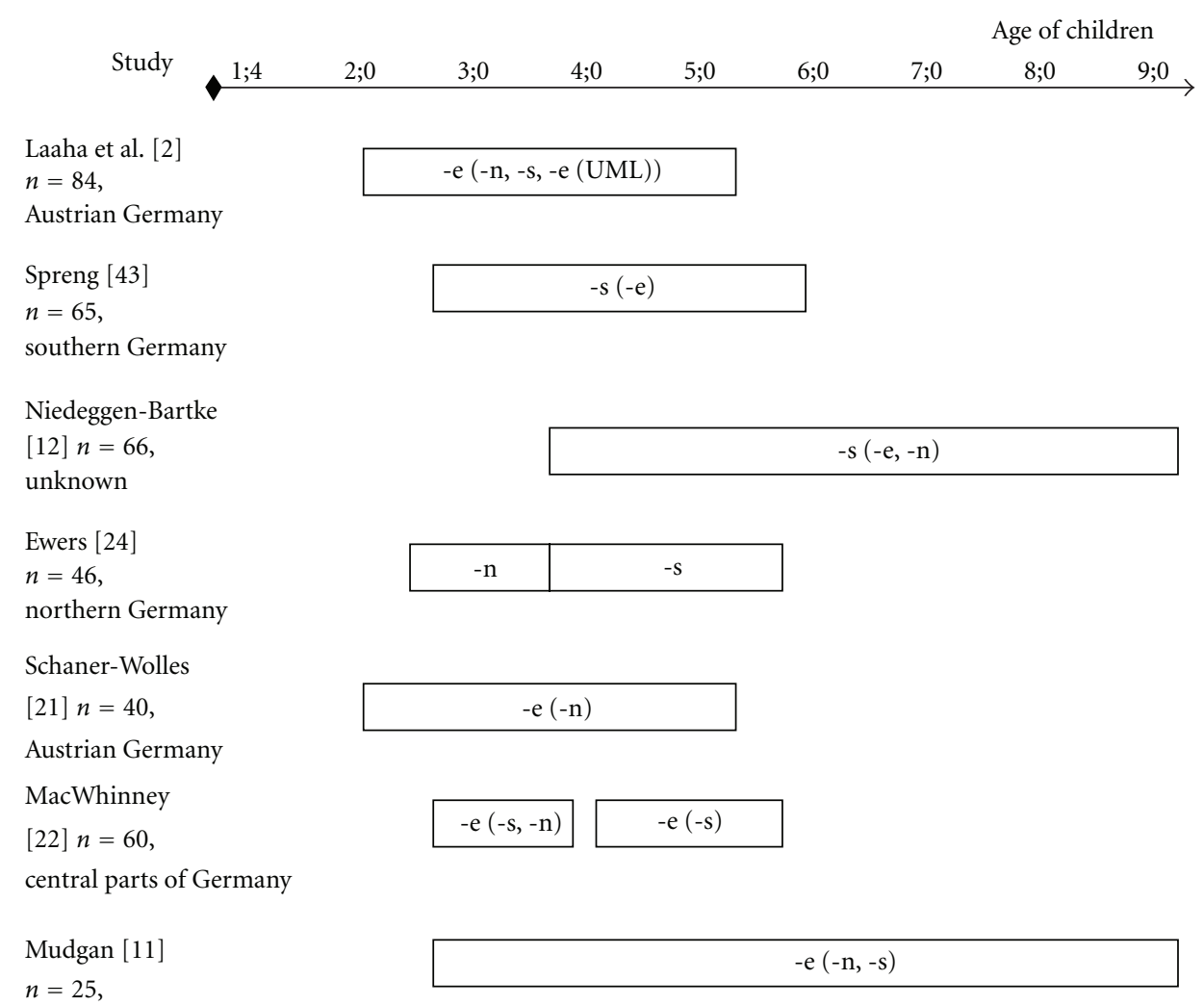

central parts of Germany

FIGURE 2: overapplications in typically developing children: elicitation studies.

learn to express the morphosyntactic function PLURAL, the application of -e is the simplest way to meet the prosodic requirement for words that do not end in a final trochee.

The heterogeneous patterns may be due to methodological factors (spontaneous speech versus elicitation tasks), but also certain characteristics of the test items used in elicitation tasks may account for the diverging patterns. In the MacWhinney [22] study, two thirds of the items were masculine or neuter. Here, the typical plural form is -e, which might have primed the use of -e for overapplications. All items used in Ewers [24] ended in a pseudosuffix, which requires a zero suffix for noun plurals. Typical errors in unimpaired plural acquisition in this context involve the addition of $-\mathrm{s}$ or $-\mathrm{n}$. Since two adjacent schwa syllables are prosodically dispreferred in German, -e, -en, and -er cannot be used after pseudosuffixes. This may explain the high proportion of $-n$ and $-s$ overapplications in Ewers' data. Moreover, Schaner-Wolles [21] discusses dialectal preferences for the use of plural markers. In southern variants of German and in Austrian German, overapplications of -n seem to be more frequently used, whereas in northern Germany the -s plural is preferred (e.g., Onkel "uncles" being the standard form, colloquial forms are Onkel- $n$ in southern Germany and Austria versus Onkel-s in northern Germany). To recapitulate, it remains an unresolved question which suffixes German children use for overapplications in the process of learning the plural system of their native language and which factors account for the choice of a specific suffix.
1.3. Plural Formation in SLI. In contrast to unimpaired plural acquisition, the acquisition of noun plurals in German children with Specific Language Impairment (SLI) has not been subject to extensive research. While verb morphology is said to be an area of weakness in SLI, Clahsen [25] stated that noun plurals are not severely impaired in SLI. Empirical findings are heterogeneous: Clahsen et al. $[8,9]$ found that plural marking in spontaneous speech is mostly correct (more than 80\%). Children with SLI studied in Bartke [7] produced more errors in spontaneous plural formation than control children on a comparable language level. The incorrect plural forms were zero endings (i.e., production of the singular) as well as overgeneralizations of -(e)n. In elicitation tasks, Veit [26] found more errors in SLI children than in normal controls. Similar to the studies on unimpaired acquisition reported above, there was no single suffix that dominated the overapplications, and there was large individual variance in the patterns.

Two German elicitation studies found differences in error patterns between children with SLI and typically developing children. Schöler and Kany [27] compared children with SLI aged $7 ; 5$ to $10 ; 4$ with age-matched controls in an elicitation task and found that in nonword plural-task children with SLI applied predominantly the suffix -(e)n, while the typically developing children preferred -e. Similarly, Bartke [7] conducted an experiment on plural formation with existing words and observed that children with SLI used -(e)n more frequently than -s or -e. On the contrary, controls used -s or 
-e, but never -(e)n for their overapplications. Given that the elicitation task of Schöler and Kany [27] was based on nonwords, and that Bartke's analysis was based on only ten errors produced by three language-impaired children, it remains to be seen whether the reported findings point to qualitative differences in the development of the plural system in typically developing children and children with SLI. The observation that children with SLI may choose other suffixes than typically developing children needs further exploration. Assuming that the choice of suffixes for overgeneralizations depends on frequency, children with SLI may select a highly frequent suffix for their overgeneralizations. Oetting and Rice [28] reported that pluralization skills of Englishspeaking children with SLI are affected by input frequency to a greater extent than the skills of normally developing children. The authors put forward a hypothesis that it takes longer for the plural system of children with SLI to become independent of frequency effects [28]. A similar suggestion was made by [29] for Finnish. In a plural formation task, unimpaired subjects aged 10 to 11 years performed better than SLI subjects of the same age. The children with SLI produced significantly fewer correct responses especially in the low-frequency words. A qualitative analysis of the data showed that the low performance of the SLI group was due to a tendency to overgeneralize a frequent plural affix over other infrequent affixes [29]. It is well known that children with SLI need more exposure to the input than typically developing children. For lexical acquisition, Gray [30] found that children with SLI have to hear a new word twice as many times as their peers before comprehending it. Hoff and Naigles [31] also emphasized that there is substantial evidence for the influence of input frequency on word learning. Frequency seems to be particularly relevant when the outcome measure is production based because frequent presentations of a word in the input provide more opportunities to obtain information. Therefore, it seems reasonable to assume that frequency accounts for the use of suffixes in the overgeneralization pattern of German children with SLI.

In the light of present empirical results on plural acquisition in German, there are still some open questions worth addressing. Basically, findings are inconsistent with respect to the developmental sequence in which plural affixes are mastered and with respect to the question which suffixes are predominantly overapplied. Furthermore, data are sparse concerning plural formation in SLI in comparison to both age-matched and language-matched children. It is still unclear whether children with SLI show a simple delay in their morphological skills or whether they produce particular kinds of errors that are unusual for typical language acquisition. Finally, an aspect that has hardly been addressed so far is the interplay between prosodic and morphological factors in plural formation.

1.4. Aims and Hypotheses. We conducted two studies using the same plural elicitation task. Study 1 investigates the developmental course of plural formation in 60 unimpaired children split over three age groups. Study 2 investigates the performance of children with SLI in comparison to age- and MLU-matched controls. For now, only limited data are available for German comparing performance in plural marking in children with SLI and MLU-matched children, not to mention a comparison of SLI with MLU- and agematched groups. In both studies, we address the following questions.

(1) Overall performance: when do children master the German plural system? Here, improvement with age was expected. However, we did not expect full mastery of the complex plural system even by the age of six. Based on the well-established finding that problems with grammatical morphology are a key characteristic of SLI (see $[32,33]$ ), a poorer performance of children with SLI compared to agematched children was assumed. In line with Clahsen et al. [9] and Oetting and Rice [28], we expected that children with SLI perform at the level of MLUmatched children.

(2) Contexts of errors: do children master certain plural forms more easily than others? First, it is assumed that children produce fewer errors with high frequent plural nouns than with low frequent nouns. Second, given the conflicting empirical results concerning the developmental course of plural suffixes in German, we aimed to find evidence for the hierarchy of difficulty in a larger sample of typically developing children. Another question that was addressed was concerned with whether the developmental course of plural forms in children with SLI differs from typical development? Concerning the hierarchy of difficulty of the suffixes, it was assumed that the profiles of children with SLI are similar to those of their language-matched peers.

(3) Error types: what kind of errors predominate in children's incorrect responses? Our objective was to investigate the error types in more detail than in previous studies by calculating the proportion of no markings, substitutions, additions, and partial markings. Do error patterns change with age? Do children with SLI differ with respect to error types from age- and MLU-matched controls? Based on existing results, we expected comparable patterns in SLI- and MLU-matched children.

(4) Overapplication patterns: which suffixes are predominantly used in overregularizations? Given the considerable heterogeneity in previous elicitation studies (see Figure 2), we aimed at differentiating preferences for certain suffixes separately for addition and substitution errors. We expected that additions with -s or -n occur in the context of words with no overt plural marking. Since these noun stems already end in a schwa syllable (pseudo-suffix), any suffix other than -s or -n would lead to two adjacent weak syllables. For substitutions, a preference for -e was expected for typically developing children in line with the literature. An additional hypothesis states that children with SLI may show subtle differences in their 
TABle 2: Participants in study 1.

\begin{tabular}{lcccc}
\hline Group & $n=$ & Age & Mean age & Sex \\
\hline 1 & 20 & $3-4$ & $3 ; 4$ & 11 girls \\
2 & 20 & $4-5$ & $4 ; 5$ & 7 girls \\
3 & 20 & $5-6$ & $5 ; 5$ & 10 girls \\
\hline
\end{tabular}

choice of suffixes for overapplications. The studies of Bartke [7] and Schöler and Kany [27] suggest that children with SLI tend to prefer -(e)n to a greater extent than typically developing children.

(5) Prosodic analysis: as outlined in the introduction, typical plural forms in German are constrained by the prosodic requirement to end in a final trochee. Do children obey or violate this constraint during plural acquisition? Furthermore, it has been suggested that "aspects of prosody may be a problematic area in children with SLI" [34]. Following this assumption, one possible finding may be that children with SLI produce more prosodically marked plural forms than the typically developing children, that is, forms not ending in a final trochee.

\section{Method}

2.1. Participants. Participants in study 1 were 60 German children between 3 and 6 years of age (see Table 2). All children acquired German as their first language. No language impairments or other developmental disorders were reported. The children lived in the northern part of Germany, where they were tested individually in their kindergarten by a trained graduate student of speech and language pathology.

Eight children with SLI aged from 4;0 to 5;0, and two control groups participated in study 2. The first control group consisted of eight typically developing children of the same age (henceforward referred to as AGE group), and the second was represented by eight younger children $(2 ; 8$ to 3;5 years) with comparable MLU (henceforward MLU group). All children were monolingual German speakers who lived in Berlin and surrounding areas. Other developmental disorders or hearing impairments were excluded by means of a questionnaire filled out by the parents. For all children, recordings of spontaneous speech were obtained and transcribed in CHAT format. At least 100 utterances of every child were transcribed. MLU in words was determined with the program CLAN (cf. [35, 36]). Age and MLU of the subjects are listed in Table 3.

Age-appropriate language development of the control children was assessed by a spontaneous speech analysis and by parental report. The following criteria were used to identify subjects in the SLI group: (a) diagnosed as language impaired by a certified speech-language pathologist, (b) normal hearing and medical history, (c) scoring significantly below age level on a standardized German test of language abilities ( $t$-scores at or below 35 in one ore more subtests). Children with SLI were recruited in clinical practices, where they had already been diagnosed as having
SLI by a certified speech-language pathologist. The children's medical histories and medical records assured normal hearing, normal neurological status, and normal nonverbal intelligence, and no pervasive disorders. In order to confirm the diagnosis of language impairment and to describe the children's language problems in more detail, a standardized German test called PDSS ("Patholinguistic Assessment of Developmental Language Disorders," [37]) was additionally applied to all SLI subjects. This assessment battery includes tests of phonological, morphological, syntactic, lexical, and semantic abilities in German. Table 4 gives an overview of the $t$-values and percentiles for a range of subtests from the PDSS. It can be seen that all subjects had $t$-scores of 35 or less in at least two subtests. Qualitative phonological analyses were part of the PDSS as well. The children's phonological abilities are shown in Table 5. Phonological impairment was obvious for seven of the eight subjects, who showed substitutions of consonants and reductions of consonant clusters. One subject showed only articulation disorder (mispronunciation of $/ \mathrm{s} /$ and $/ \mathrm{z} /$ ).

There were no significant differences between children with SLI and age-matched controls with respect to age in months $(U=19.5, P>.19)$, but MLU was significantly higher in the unimpaired controls $(U=5.0, P<.01)$. Children with SLI differed from MLU controls with respect to age $(U=0.00, P<.001)$ but not with respect to MLU $(U=26.0, P>.52)$.

2.2. Materials and Procedure. A plural elicitation task was constructed comprising words covering all German plural forms. The test items were 44 word stimuli reflecting the German plural suffixes. For item selection, we used the classification of plural types, as proposed by Eisenberg (see Table 1). The items were evenly distributed over these plural types. All items were monomorphemic and balanced for gender. Four items were provided for each plural type. For a complete item list, see Table 11 at the end of the paper.

Examples for plural items:

(1a) das Schwein—die Schweine "pig-pigs,"

(1b) der Hut-die Hüte "hat-hats,"

(1c) das Kissen-die Kissen "pillow-pillows,"

(1d) der Vater-die Väter "father-fathers,"

(2a) die Uhr-die Uhren "clock-clocks,"

(2b) die Feder-die Federn "feather-feathers,"

(3a) der Prinz-die Prinzen "prince-princes,"

(3b) der Affe-die Affen "ape-apes,"

(4) das Bild—die Bilder "picture-pictures,"

(5) die Kuh—die Kühe "cow-cows."

(6) der Teddy—die Teddys "teddy-teddies,"

Frequency of the test items was determined with the help of the German CELEX database ([38]; spoken word frequency of the pluralized word per million). The mean frequency of the plural nouns was 9.53 with a standard deviation of 22.84. In order to compare performance for 
Table 3: Participants in study 2 (age and MLU).

\begin{tabular}{lccccccccccc}
\hline SLI & Age & Sex & MLU & MLU-controls & Age & Sex & MLU & Age-controls & Age & Sex & MLU \\
\hline S-L1 & $4 ; 0$ & $\mathrm{f}$ & 3.19 & M-A & $2 ; 8$ & $\mathrm{f}$ & 4.26 & A-M1 & $4 ; 0$ & $\mathrm{~m}$ & 3.90 \\
S-J1 & $4 ; 3$ & $\mathrm{f}$ & 3.19 & M-W & $2 ; 9$ & $\mathrm{f}$ & 2.86 & A-L1 & $4 ; 0$ & $\mathrm{f}$ & 3.99 \\
S-M & $4 ; 5$ & $\mathrm{f}$ & 3.77 & M-S & $2 ; 10$ & $\mathrm{f}$ & 3.50 & A-M2 & $4 ; 2$ & $\mathrm{~m}$ & 4.61 \\
S-J2 & $4 ; 6$ & $\mathrm{f}$ & 3.47 & M-L & $2 ; 10$ & $\mathrm{f}$ & 3.76 & A-S & $4 ; 2$ & $\mathrm{f}$ & 3.58 \\
S-L2 & $4 ; 7$ & $\mathrm{f}$ & 3.07 & M-P & $2 ; 11$ & $\mathrm{f}$ & 3.00 & A-N & $4 ; 2$ & $\mathrm{f}$ & 4.38 \\
S-J3 & $4 ; 9$ & $\mathrm{f}$ & 2.54 & M-T & $3 ; 1$ & $\mathrm{~m}$ & 3.35 & A-P & $4 ; 7$ & $\mathrm{f}$ & 3.94 \\
S-S & $4 ; 11$ & $\mathrm{f}$ & 3.16 & M-H & $3 ; 2$ & $\mathrm{f}$ & 3.32 & A-L2 & $4 ; 11$ & $\mathrm{f}$ & 4.26 \\
S-F & $5 ; 0$ & $\mathrm{~m}$ & 3.64 & M-M & $3 ; 5$ & $\mathrm{~m}$ & 3.40 & A-A & $4 ; 11$ & $\mathrm{f}$ & 3.41 \\
mean & $4 ; 7$ & & 3.25 & & $3 ; 0$ & & 3.43 & & & $4 ; 4$ & \\
\hline
\end{tabular}

TABLE 4: Individual subject profiles: SLI group.

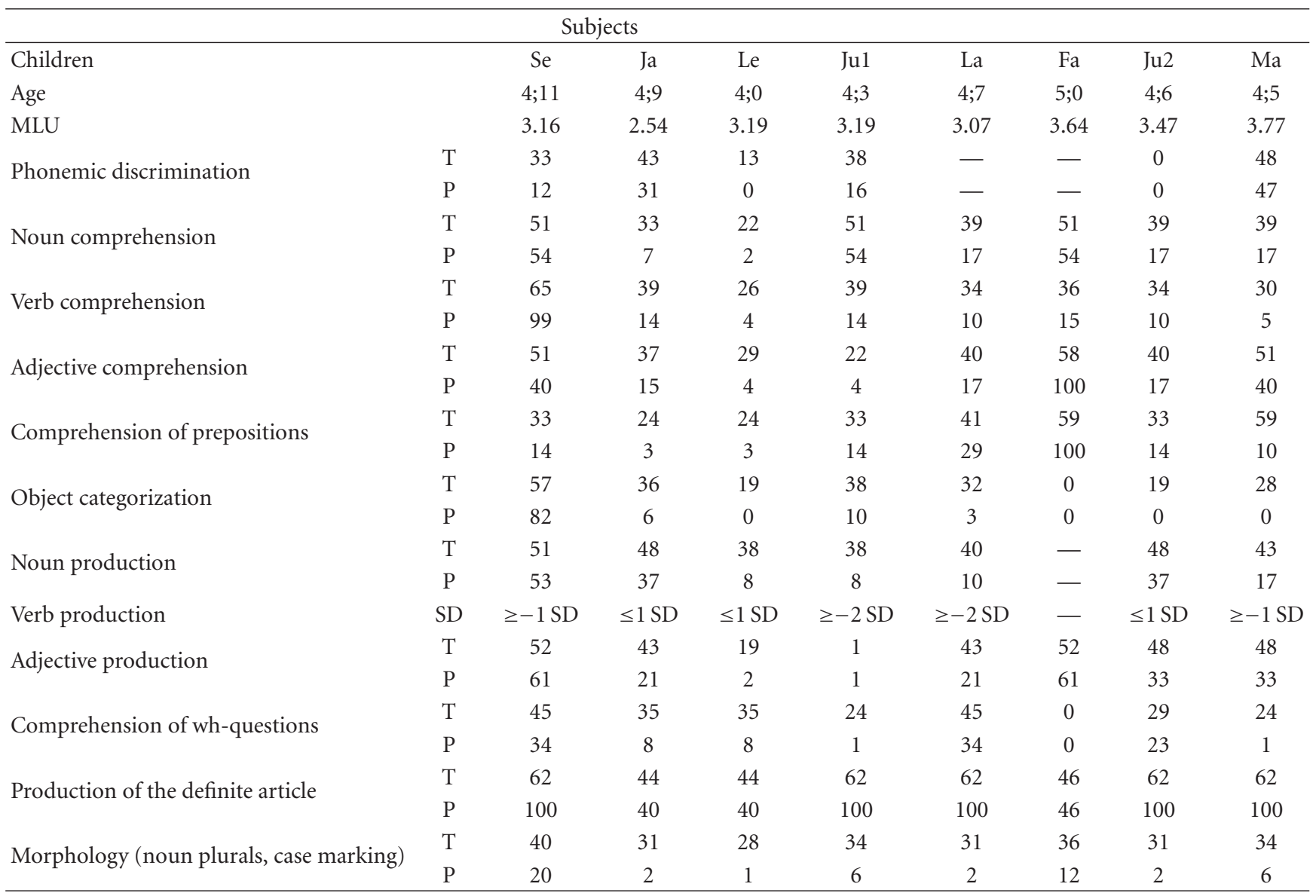

P: Percentile, T: $t$-value.

Table 5: Phonological characteristics: SLI group.

\begin{tabular}{ll}
\hline Subjects & Substitution of: \\
\hline Se & $/ \mathrm{v} /, / \mathrm{C} /, / \mathrm{x} /$ and reduction of consonant clusters \\
Ja & $/ \mathrm{p} /, / \mathrm{v} /, / \mathrm{x} /, / \mathrm{h} /$ and reduction of consonant clusters \\
Le & $/ \mathrm{b} /, / \mathrm{t} /, / \mathrm{f} /, / \mathrm{k} /, / \mathrm{v} /, / \mathrm{z} /, / \mathrm{\int} /, / \mathrm{m} /$ and reduction of consonant clusters \\
Ju1 & $/ \mathrm{d} /, / \mathrm{k} /, / \mathrm{g} /, / \mathrm{l} /, / \mathrm{R} /, / \mathrm{f} /, / \mathrm{v} /, / \mathrm{n} /, / \mathrm{t} /, / \mathrm{n} /$ and reduction of consonant clusters \\
La & $/ \mathrm{p} /, / \mathrm{v} /, / \mathrm{j} /, / \mathrm{n} /, / \mathrm{l} /, / \mathrm{J} /$ and reduction of consonant clusters \\
Fa & Phonetic impairment $(/ \mathrm{z} /, / \mathrm{s} /$ substituted by $/ \theta /, / d /)$ \\
Ju2 & $/ \mathrm{k} /, / \mathrm{g} /, / \mathrm{C} /, / \mathrm{n} /, / \mathrm{x} /$ and reduction of consonant clusters \\
Ma & $/ \mathrm{v} /, / \mathrm{t} /$ and reduction of consonant clusters \\
\hline
\end{tabular}


items with high versus low frequency, items were divided as follows: based on the median, 12 words on the upper end of the frequency distribution and 12 words on the lower end were chosen. Mean frequency of the high-frequency items was 17.75 with a range from 10 to 41 , whereas all lowfrequency items had a frequency of 0 (frequency for all items in terms of spoken word frequency of the plural form per million according to CELEX).

The method used was a sentence completion task with pictures. Colored drawings of the stimuli were presented with the single object depicted on the left and multiple objects on the right. The children were asked to produce the plural form (stimulus: "This is one ..., and these are many-"), without offering further prompts. The test was preceded by two practice items.

2.3. Data Coding. In order to calculate accuracy, the responses were coded as correct or incorrect. For real words, a response was counted as correct when the appropriate plural marker of the target language was chosen. Phonological errors had no influence on the coding of accuracy as long as the plural marker could be identified. In case of self-corrections, the correct answer was counted. As regards self-corrections that lacked the correct plural form, the last response was taken into account.

Incorrect responses were classified as follows.

(1) Addition: the child inadequately adds a plural marker (e.g., ${ }^{*}$ Messers instead of Messer "knifes").

(2) Substitution: the correct suffix is substituted by another existing plural suffix (e.g., ${ }^{*}$ Prinze instead of Prinzen "princes").

(3) Incomplete/partial marking: this error type is only possible for items that require umlaut plus suffix. Either umlaut or the plural suffix may be missing (e.g., * Küh or *Kuhe, instead of Kühe "cows").

(4) No marking: the item remains unchanged when a plural marker is required. In this case, the singular form is repeated.

(5) No reaction: the child does not answer at all or with "don't know."

(6) Others: the child responds with another word (e.g., Teddybären "teddybears" instead of Teddys "teddies"), with a diminutive form (Engelchen "angelpl./sg.dim." instead of Engel "angels"), or uses nonexisting plural markers (e.g., *Zebrate instead of Zebras "zebras").

No reactions and other responses (error types 5 and 6) were excluded from the analysis, since they are not related to the plural task itself. When classifying the remaining errors, that is, responses that resulted in the production of the target noun, but incorrectly marked for plural, we differentiated between additions, partial markings, and substitutions. Additions and substitutions were subsumed under the category "overgeneralizations" in Laaha et al. [2]. The more fine-grained distinction between substitutions and additions nevertheless seems to be necessary due to the fact that different suffixes may be used for these types of errors.

In some cases two error types had to be assigned to one single item. For example, the correct plural form of Gans "goose" is Gänse. When the child's answer was *Gansen, the error type "partial marking" was counted for the missing umlaut, and the error type "substitution" was counted because of the application of -en instead of -e. Consequently, there were more errors counted in the analysis of error patterns than in the accuracy analysis.

In order to investigate whether prosodic requirements for plural formation in German were considered, we calculated the number of responses that did not end in a final trochee (i.e., monosyllabic forms like $*$ Bärs, or words ending in two reduced syllables).

2.4. Reliability. For study 1 , four independent raters classified $20 \%$ of the data with respect to error patterns. Interrater agreement was $97.3 \%$. In the same way, four independent raters analyzed the data of four randomly chosen children from the SLI group in study 2. Interrater agreement amounted to $100 \%$.

2.5. Statistical Analysis. The data were analyzed for accuracy and error patterns. For the analysis of the error contexts, the percentage of errors in each plural condition was computed. The proportion of error types was determined by calculating the percentage of each error type (no marking, addition, substitution, partial marking) on the total number of errors excluding no and other reactions. For the in-depth analysis of overapplication patterns, the percentage of each suffix on the total number of additions or substitutions was calculated per child.

In study 1, differences between age groups with respect to overall accuracy, the proportion of error types, and suffixes used in overapplications were tested with one-way ANOVAs followed by $t$-tests corrected for multiple testing. In study 2 , nonparametrical tests were applied. Group differences were tested by the Kruskall-Wallis-test and follow-up MannWhitney $U$-tests (Bonferroni correction). In addition, singlecase statistics [39] were applied.

\section{Results}

\subsection{Study 1}

3.1.1. Overall Performance. Table 6 shows the descriptive statistics for the children's performance in the plural elicitation task.

The children's overall accuracy in plural production for words increased with age. An overall analysis of accuracy scores over groups (ANOVA) revealed a meaningful difference between groups $(F(2,57)=12.83 ; P<.001$; pes $($ partial eta square $)=.31$ ). However, there were almost no differences between three-year-old and four-year-old children $(t(38)=-.75, P<.45)$. After this plateau, accuracy improved significantly $(t(38)=4.74, P<.001$ between age groups 2 and 3). 
TABLE 6: Mean number and percentage of correct responses in typical children by age (study 1).

\begin{tabular}{lccccc}
\hline Age & Mean & SD & Minimum & Maximum & Percent correct \\
\hline $3 ; 0-4 ; 0$ & 31.25 & 5.45 & 19 & 38 & 71.0 \\
$4 ; 0-5 ; 0$ & 32.45 & 4.6 & 22 & 38 & 73.6 \\
$5 ; 0-6 ; 0$ & 37.6 & 1.54 & 34 & 40 & 85.4 \\
\hline
\end{tabular}

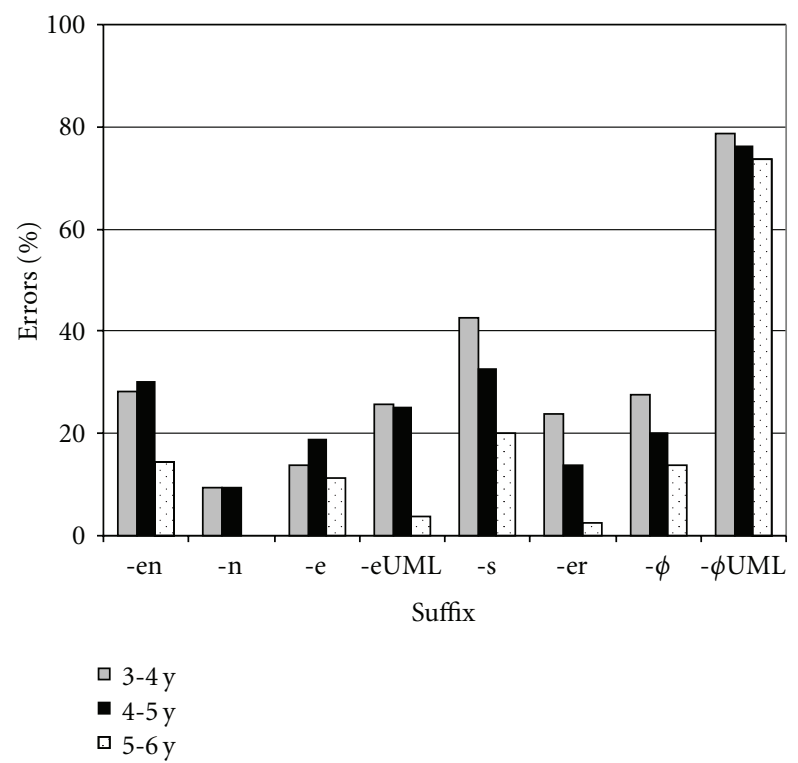

Figure 3: Percentage of errors in each plural context in typical children by age (study 1$)$.

3.1.2. Contexts of Errors. With respect to frequency, items with high frequent plural forms were compared to lowfrequency forms. Plural markings for words with high frequency were significantly better than, for the low-frequency words $(t(59)=10.86, P<.001$ for all children, $t(19)=5.56$, $P<.001$ for age group $1, t(19)=7.75, P<.001$ for age group $2, t(19)=7.34, P<.001$ for age group 3$)$.

A detailed descriptive analysis indicates which plural types were most error prone. Figure 3 shows the percentage of errors for each plural context. Suffixes that occur with different genders (see Table 1) were merged into one group per suffix, because a first error analysis did not reveal influences of gender on performance.

As can be seen in Figure 3, the plural suffixes were mastered successively in the course of development. By age 5 , the proportion of errors was less than $25 \%$ for all suffixes except for pure umlauts. More than $70 \%$ of the pure umlaut items were produced incorrectly throughout the whole period. Younger children also produced a lot of errors with the -s plural, whereas -n (both in the feminine context and in the marked masculine context) was nearly correct from the beginning.

3.1.3. Error Types. A qualitative analysis of error types focuses on the question how differently error patterns are distributed over age groups. Figure 4 shows the proportion of

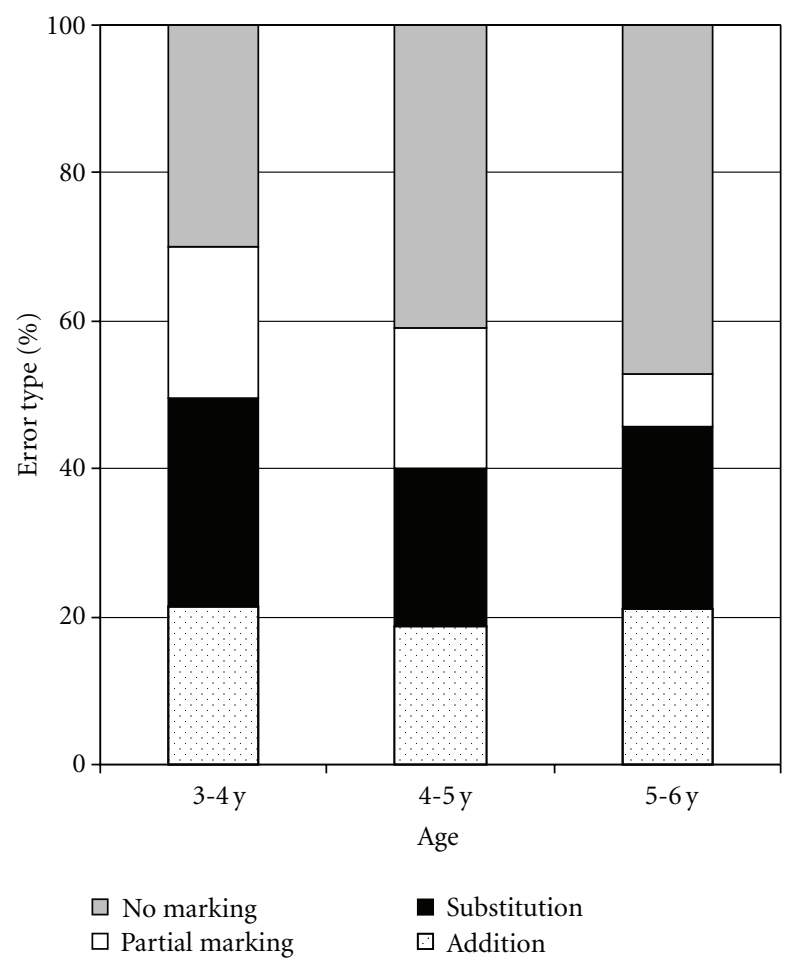

FIGURE 4: Error patterns observed in typical children by age (study 1 ).

the error-types: no marking, partial marking, addition, and substitution in the three age groups.

An omnibus analysis of variance over the factors error type and age (between-subjects factor) revealed a main effect for error type and age, and an interaction between both factors (see Table 7). Post hoc $t$-tests demonstrated a significant decrease of partial markings as a function of age. The proportion of no markings increased with age. Errors were classified as no markings, when the singular form was repeated. There are two subtypes of this kind of error. First, the child does not apply a plural suffix when required (*Burg instead of Burgen "castles"). Second, the child omits the umlaut when the plural form requires umlaut but a zero suffix (*Faden instead of *Fäden "threads"). In children between 3 and 5 years (age groups 1 and 2), both subtypes of "no markings" were evenly distributed, whereas for the oldest children $84 \%$ of "no markings" occurred in the context of words requiring pure umlaut. Thus, the apparent increase of repetitions of the singular form is due to the omission of umlaut. As illustrated in Figure 3, pure umlaut is the most difficult context even for older children, which is again reflected by the error type analysis. 
TABle 7: ANOVA over the factor AGE-GROUP ((1) 3-4 years old, (2) 4-5 years old, (3) 5-6 years old) and Error-Type (no markings, addition errors, substitution errors, and partial markings). Post hoc analyses calculated $t$-test over group contrasts $(1,2),(1,3)$, and $(2$, $3)$. For pairwise contrasts of age-groups, $P$-values are Bonferronicorrected to $P<.017$.

\begin{tabular}{lc}
\hline & ANOVA \\
\hline Main effect AGE group: & $F(2,57)=4.6, P<.02$, pes: .139 \\
Main effect error type: & $F(3,171)=22.45, P<.001$, pes: .283 \\
Interaction: & $F(6,171)=3.3, P<.02$, pes: .104 \\
\hline Error type & $T$-tests \\
\hline & 1 versus 2: $t(38)=-2.4, P<.03$ \\
No markings & 1 versus 3: $t(38)=-2.5, P<.02$ \\
& 2 versus 3: $t(38)=-.92, P>.36$ \\
\hline & 1 versus 2: $t(38)=.50, P>.62$ \\
Addition errors & 1 versus 3: $t(38)=.37, P>.97$ \\
& 2 versus 3: $t(38)=-.43, P>.67$ \\
\hline Substitution errors & 1 versus 2: $t(38)=2.1, P<.05$ \\
& 1 versus 3: $t(38)=.99, P>.32$ \\
& 2 versus 3: $t(38)=-.86, P>.39$ \\
\hline & 1 versus 2: $t(38)=.54, P>.59$ \\
Partial markings & 1 versus 3: $t(38)=4.2, P<.001$ \\
& 2 versus 3: $t(38)=3.9, P<.001$ \\
\hline
\end{tabular}

3.1.4. Overapplication Patterns. An in-depth analysis of the incorrect responses revealed which suffixes were used inappropriately. From Figure 5 it transpired that if some material was added, then the $-\mathrm{s}$ was selected in more than $60 \%$ of the cases. In particular, -s was added to nouns with canonical zero-marking with or without umlaut (e.g., *Vaters instead of Väter "fathers"). Furthermore, umlaut was added to items where no umlaut is demanded. This seemed to be an item-specific phenomenon, because umlaut was added to the item Brot in nearly all cases $\left({ }^{*}\right.$ Bröte instead of Brote "bread" pl). In all cases with partial marking, Umlaut was omitted (e.g., *Huhne instead of Hühner "chicken"). If affixes were substituted, then it was an -e in more than $60 \%$ of substitution errors (e.g., *Bäre instead of Bären "bears"), followed by -(e)n.

The next step was to investigate whether the apparent preferences for $-\mathrm{s}$ in additions and for -e in substitutions were meaningful and whether there were developmental trends in the overapplication patterns. With respect to additions, an omnibus analysis of variance over the factors suffix (-s and umlaut) and age (between-subjects factor) revealed no main effects for suffix and age, and no interaction. With respect to substitutions, an omnibus analysis of variance over the factors suffix (-e and -(e)n) and age (between-subjects factor) revealed no main effect for age, but a main effect for suffix $(F(1,57)=19.11 ; P<.001$; pes =.25) and no interaction. This confirms that typically developing children strongly prefer -e-plurals in substitutions.

3.1.5. Prosodic Analysis. Finally, the proportion of prosodically marked forms (i.e., forms that did not end in a final

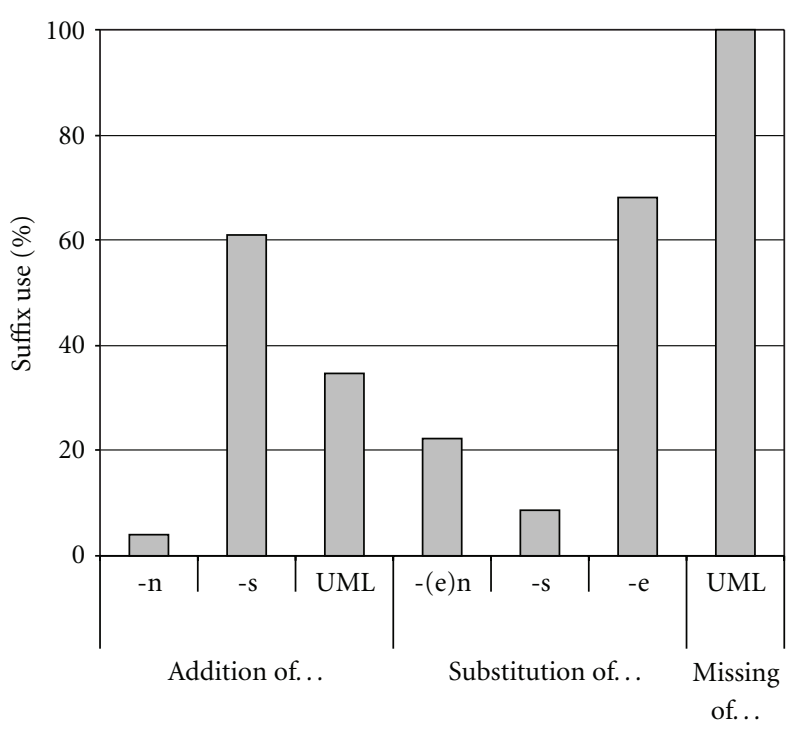

Figure 5: Analysis of incorrect responses (in per cent) produced by typical children (study 1 ).

trochee) in relation to all errors (except for no markings) was calculated. The prosodic constraint was violated in less than $0.4 \%$ of all produced plural forms. The rare prosodically marked forms consisted exclusively of monosyllabic stems plus -s instead of bisyllabic plural forms (e.g., ${ }^{*}$ Kuhs, instead of Kühe, "cows"). Forms with two adjacent final reduced syllables never occurred.

\subsection{Study 2}

3.2.1. Overall Performance. In general, the number of analyzable stimuli differs between groups: $76.1 \%$ in the MLU group, $96.8 \%$ in the SLI group, and $96 \%$ in the AGE group. The lowest amount of analyzable stimuli in the MLU group results from the fact that the younger children refused to respond in more cases than the older children in the SLI and AGE groups. This may be due to the limited vocabularies of the younger children.

Descriptive statistics for the performance of the three populations tested in study 2 are provided in Table 6 . An overall comparison of the group means yielded a meaningful difference (Kruskal-Wallis test: $P<.003$ ). Testing pairwise contrasts, we observed that the children with SLI performed at the level of the MLU-matched children $(U=30.5$, $P>.88$ ). At the same time, children with SLI made significantly more errors than unimpaired children of the same age $(U=3.5, P<.01$, Bonferroni-corrected $P$-level: .025).

3.2.2. Context of Errors. Next to overall performance, we also investigated the contexts where the errors occurred. All children performed better on high-frequency plurals forms than on items with low frequency (analysed by Wilcoxontests). The frequency effect was significant in the SLI group $(z=-2.32, P<.03)$ and in the AGE group $(z=-2.55$, $P<.02)$. There was a tendency in favor of the frequent plural 
TABLE 8: Mean number and percentage of correct responses in typical and language-impaired children (study 2).

\begin{tabular}{lccccc}
\hline Group & Mean & SD & Minimum & Maximum & Percent correct \\
\hline SLI & 20 & 6.05 & 13 & 29 & 45.5 \\
MLU & 18.75 & 6.5 & 10 & 28 & 42.6 \\
AGE & 31.25 & 3.37 & 26 & 37 & 71.0 \\
\hline
\end{tabular}

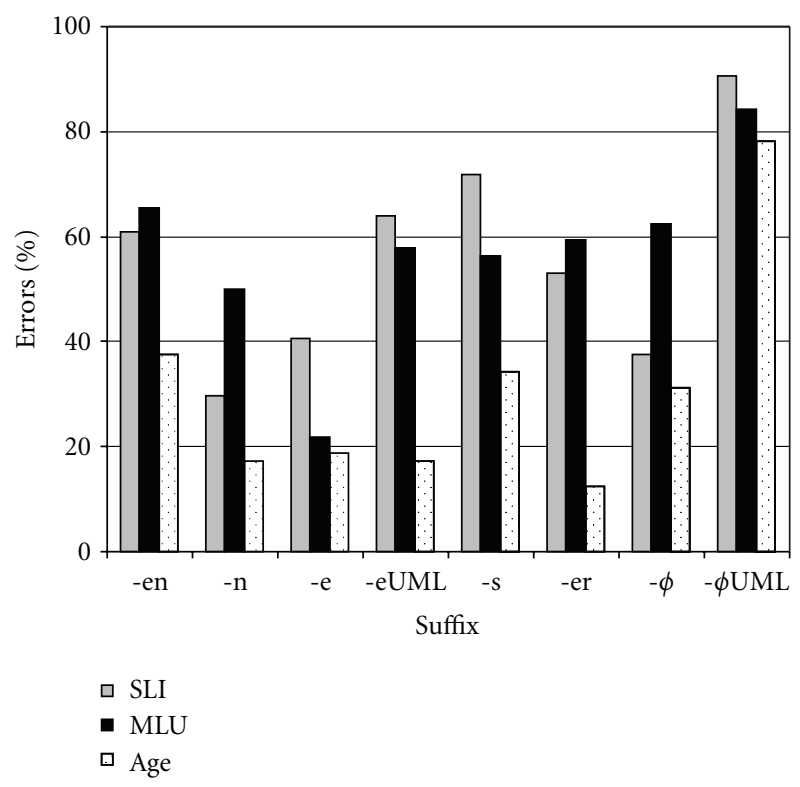

Figure 6: Percentage of errors for each plural context in children with SLI and control groups (study 2).

forms for the youngest children in the MLU group as well $(z=-1.83, P=.068)$.

In addition, the percentage of errors in each plural context was calculated. Figure 6 illustrates the percentage of errors in each plural context.

Again, pure umlauts are more difficult than all other types in all three groups. This prominent difficulty replicates findings observed in Study 1. Figure 6 shows that - s plurals were more difficult for children with SLI than for unimpaired children. Furthermore, children with SLI produced twice as much errors with -e-plurals than the control groups.

3.2.3. Error Types. Figure 7 illustrates the proportions of error-types observed in the three groups. Table 9 first provides the statistical results in which the proportions of error-types were analyzed in correlation with the total number of errors. Analyses utilizing the Kruskal-Wallis test for each error-type (zero-marking, partial marking, addition errors, and substitution errors) revealed a significant group effect for substitution errors only. Pairwise comparisons of the children with SLI with each of the control groups showed that the performance of the children with SLI differed significantly from the AGE group with respect to the proportion of substitution errors. The SLI-group produced fewer substitution errors. Note that the statistical results did not reflect that the children with SLI displayed a high

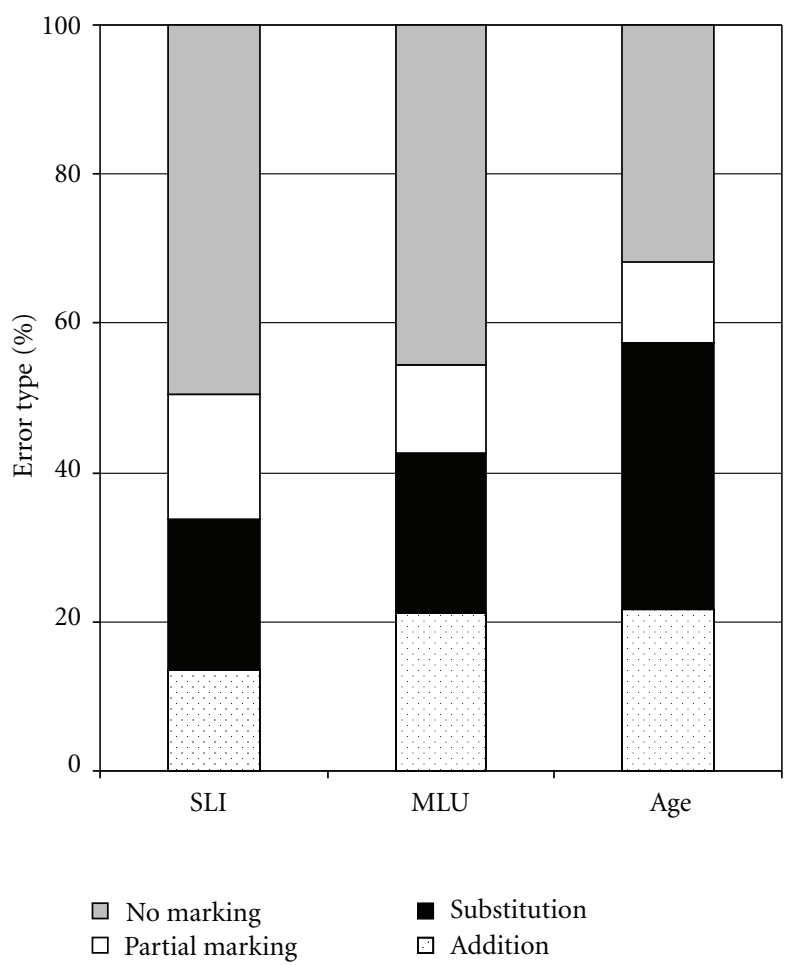

FIGURE 7: Error patterns (in per cent) observed in children with SLI and control groups (study 2).

proportion of "no marking" errors (i.e., repetition of the singular form). Undoubtedly this lack of effect is owing to the fact that children with SLI generally produced more errors. The calculation of the proportion of error types so far ignores that the groups produced different total numbers of errors. Therefore, the proportion of error types was additionally calculated in relation to the total number of analyzable responses (correct responses and errors), resulting in a comparable sample size. Table 9 now shows that children with SLI produced more partial markings and more "no marking" errors than the age-matched controls.

Again, we analyzed which kind of error led to the repetition of the singular form (error type: "no marking"). In the group of the age-matched control children, $55 \%$ of no markings occurred in the context of words requiring pure umlaut, that is, the children simply omitted the umlaut. This is a similar proportion as observed in the children of study 1 of the same age ( $42 \%$ in age group 2$)$. However, children with SLI as well as the younger MLU-matched children produced a high proportion of real suffix omissions (e.g., *Gans instead of Gänse, "geese"): only 18\% (SLI) and 
TABLE 9: Comparison of the proportion of each error type over the factor group (SLI, MLU, AGE) and pairwise group contrasts (SLI, MLU) and (SLI, AGE) for substitution errors. For pairwise contrasts of the SLI group with each control group, $P$-values are Bonferronicorrected to $P<.025$.

\begin{tabular}{lcc}
\hline Error type & Kruskal-Wallis-test & $\begin{array}{c}\text { Mann-Whitney } \\
U \text {-test }\end{array}$ \\
\hline No markings & $P>.50$ & - \\
Addition errors & $P>.41$ & - \\
Substitution errors & $P<.055$ & SLI versus MLU: \\
& & $U: 27.5, P>.63$ \\
Partial markings & $P>.23$ & SLI versus AGE: \\
& & $U: 11.0, P<.03$ \\
\end{tabular}

$10 \%$ (MLU group) of no markings were due to omission of umlaut.

3.2.4. Overapplication Patterns. In a further step, we performed a more fine-grained analysis for addition and substitution errors, in which we focus on the qualitative usage of certain suffixes. The main objective was to find out whether the test groups preferred different suffixes in additions and substitutions. Therefore, the proportion of additions or substitutions involving a certain suffix were calculated on the basis of the total number of addition or substitution errors per child. For additions, Figure 8 shows that children with SLI preferred to add the suffix -n (e.g., *Vogeln instead of Vögel "birds"), while both groups of normally developing children preferred the addition of -s (e.g., *Vogels instead of Vögel "birds"). As can be seen from the summary of statistical results obtained for the analysis of addition errors in Table 10, both types of differences are meaningful. In particular, children with SLI differed not only in comparison to the age-matched group with respect to the additions but also to the MLU-matched group (tendency) with respect to $-(e) n$.

Similar group differences were found for substitutions (Figure 9). Although there were no statistically significant effects (see Table 9), both control groups numerically preferred -e (e.g., * Burge instead of Burgen "castles"), followed by $-(e) n$, whereas children with SLI showed the inverse pattern (-(e)n for -e, e.g., * Fischen instead of Fische "fishes"). The preference of $-(\mathrm{e}) \mathrm{n}$ in substitutions corresponds to the addition patterns, where children with SLI also used -(e)n more often than the control groups. Although we did not find a statistical group effect for the preference of the suffix (e) $n$ in the SLI-group, it is noteworthy that two children with SLI (Le and Fa) stood out in the number of overapplications with the suffix -(e)n. We, therefore, compared the number of substitutions with -(e)n of these two SLI children with the mean number of -(e)n substitutions observed in each control group utilizing a single-case analysis by Crawford and Garthwaite [39]. As a result, we obtained significant differences for Le and $\mathrm{Fa}$ in comparison to each control group (Le versus MLU-matched: $P<.004$; estimated effect size: Point: 4.68, 95\% CI: 2.181 to 7.164; Le versus AGE-matched:

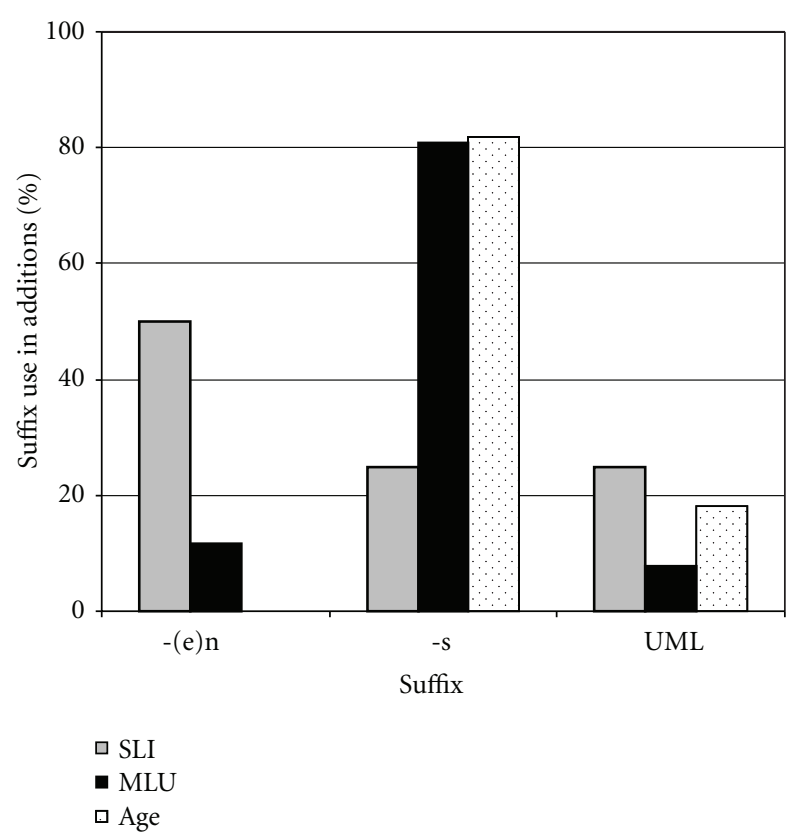

Figure 8: Incorrect addition (in percent) of plural suffixes in children with SLI and control groups (study 2).

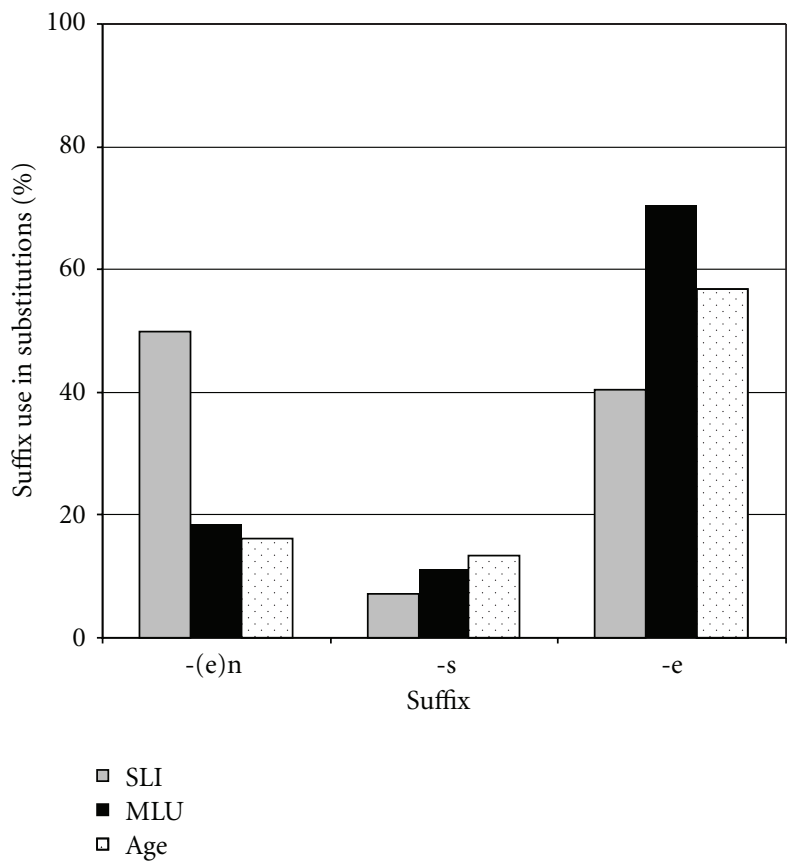

FIgURE 9: Substitution of plural suffixes in children with SLI and control groups (study 2).

$P<.02$; estimated effect size: Point: $3.573,95 \%$ CI: 1.605 to 5.513; Fa versus MLU-matched: $P<.001$; estimated effect size: Point: 5,880, 95\% CI: 2.792 to 8.960; Fa versus AGE-matched: $P<.004$; estimated effect size: Point: 4.562 , 95\% CI: 2.119 to 6.987$)$. No single child with such a strong preference for the overapplication of $-(e) n$ was observed in either of the control groups. 
TABLE 10: Qualitative comparison of addition and substitution errors. For pairwise contrasts of the SLI group with each control group, $P$-values are Bonferroni-corrected to $P<.025$.

\begin{tabular}{lcc}
\hline Error type & Kruskal-Wallis-test & Mann-Whitney $U$-test \\
\hline Addition of $-\mathrm{n}$ & $P<.007$ & SLI versus MLU: $U=14.5, P<.05$ \\
& & SLI versus AGE: $U=8.0, P<.005$ \\
Addition of -s & $P<.016$ & SLI versus MLU: $U=27.0, P>.58$ \\
& & SLI versus AGE: $U=3.0, P<.003$ \\
Substitution with -e & $P>.59$ & SLI versus MLU: $U=28.5, P>.70$ \\
& & SLI versus AGE: $U=22.0, P>.29$ \\
Substitution with -(e)n & $P>.41$ & SLI versus MLU: $U=22.0, P>.24$ \\
& & SLI versus AGE: $U=24.0, P>.36$ \\
\hline
\end{tabular}

3.2.5. Prosodic Analysis. Finally, an analysis of the prosodic structure of the incorrect plural forms revealed that for all groups the proportion of forms not ending in a final trochee was less than $3 \%$. As in the first study, children produced some monosyllabic forms ending in an - s plural, but no form occurred including two adjacent reduced syllables.

\section{Discussion}

The present study examined the acquisition of German noun plurals in typically developing children and children with SLI in an elicitation task. We will now address and discuss the findings in the order of the leading questions outlined in the Section 1.4 .

4.1. Overall Performance. The general picture that emerges from the data analysis may be characterized as follows: in typically developing children, performance with noun plurals remained on a plateau between age $3 ; 0$ to $4 ; 11$; afterwards there was a marked improvement. Between 5 and 6 years of age, $80 \%$ of the children's responses were correct, suggesting that full mastery of the German plural system is achieved relatively late in first language acquisition. The observation that complex inflectional systems stabilize relatively late has been shown for other languages as well (e.g., [40], for verb inflection in Finnish, [41] on number inflection in Palestinian Arabic).

As expected, children with SLI clearly fell behind their unimpaired peers in plural marking. Their error rate was significantly higher compared to typically developing children of their own age. Rather, the children with SLI performed at the level of MLU-matched children who were one and a half year younger. Thus, our results do not converge with Clahsen's suggestion "that the acquisition of German noun plural marking is not impaired in SLI" [25]. The differing conclusions may result from the fact that Clahsen et al. $[8,25]$ did not compare the performance of children with SLI with the performance of age- and/or languagematched control groups using elicitation tasks. Our results did confirm the findings of Oetting and Rice's [28] study on English plural acquisition. Using a similar pluralization task with three groups of children of the same age as our subjects, they found significantly better performance in age-matched children than in children with SLI, but no significant differences between their SLI subjects and their MLU-matched control group. Oetting and Rice concluded that children with SLI demonstrate the ability to produce noun plurals as readily as children with equivalent language abilities [28]. Thus, plural formation is neither an area of specific difficulty, nor an area of specific strength in SLI, because the performance of the children with SLI corresponded to their overall language capacities measured by MLU.

4.2. Context of Errors. In general, the same effects for frequency were found in all groups of children of different ages, that is an advantage for highly frequent plural forms. Obviously, children are more familiar with high frequent words, which results in a better performance in the plural task. Children with SLI showed a similar advantage for highly frequent words as typically developing children.

Concerning the developmental sequence of the various plural markers, our results mainly converge with findings from other German studies in that -e and -e plus umlaut were mastered early and easily, whereas -s and -er plurals caused more problems. The outstanding mastery of -e in comparison to the other plural suffixes may reflect the fact that this ending is the unmarked way to indicate the function Plural (see [6] as outlined in the introduction). For children who learn to express the morphosyntactic function PLURAL, the application of -e to monosyllabic word stems seems to be the simplest way to meet the prosodic requirement for German plural forms, namely, to end in a bisyllabic trochee. Typically developing children seem to be sensitive to this prosodic constraint before they are able to choose the appropriate suffix.

Previous studies have been equivocal with respect to the suffix -(e)n. In contrast to Laaha et al. [2], who found that -(e)n was mastered rather late, our data show that -n (after word stems with final schwa) was produced very early and with very low error rates, while the -en suffix was mastered later. The discrepancy in the findings may be due to fact that Laaha et al. [2] merged $-n$ and -en into one suffix category. Outstanding and persisting problems emerged with the pure umlaut. In this case all children, regardless of age and language ability, had enormous difficulty. The difficulty of the pure umlaut confirms the results of Ewers [24] and 
TABLE 11: Item list.

Frequency group

Singular form Plural form English translation hf: high frequency

lf: low frequency

\begin{tabular}{|c|c|c|c|}
\hline Affe & Affe-n & apes & hf \\
\hline Feder & Feder-n & feathers & \\
\hline Hase & Hase-n & rabbits & \\
\hline Löwe & Löwe-n & lions & \\
\hline Rabe & Rabe-n & ravens & \\
\hline Schere & Schere-n & scissors & \\
\hline Tasche & Tasche-n & bags & \\
\hline Zwiebel & Zwiebel-n & onions & lf \\
\hline Bär & Bär-en & bears & \\
\hline Burg & Burg-en & castles & \\
\hline Elefant & Elefant-en & elephants & \\
\hline Frau & Frau-en & women & \\
\hline Prinz & Prinz-en & princes & lf \\
\hline Tür & Tür-en & doors & \\
\hline Uhr & Uhr-en & clocks & hf \\
\hline Zeh & Zeh-en & toes & \\
\hline Brot & Brot-e & breads & \\
\hline Fisch & Fisch-e & fishes & hf \\
\hline Pilz & Pilz-e & mushrooms & \\
\hline Schwein & Schwein-e & pigs & hf \\
\hline Baum & Bäum-e & trees & hf \\
\hline Fuß & Füß-e & feet & \\
\hline Gans & Gäns-e & geese & lf \\
\hline Hut & Hüt-e & hats & \\
\hline Kuh & Küh-e & cows & lf \\
\hline Nuss & Nüss-e & nuts & lf \\
\hline Topf & Töpf-e & pots & hf \\
\hline Maus & Mäus-e & mice & lf \\
\hline Bild & Bild-er & pictures & hf \\
\hline Glas & Gläs-er & glasses & hf \\
\hline Huhn & Hühn-er & hens & \\
\hline Kleid & Kleid-er & dresses & hf \\
\hline Lkw & Lkw-s & vans & lf \\
\hline Lok & Lok-s & engines & lf \\
\hline Teddy & Teddy-s & teddies & lf \\
\hline Zebra & Zebra-s & zebras & If \\
\hline Engel & Engel & angels & hf \\
\hline Kissen & Kissen & pillows & \\
\hline Roller & Roller & scooter & lf \\
\hline Messer & Messer & knifes & \\
\hline Faden & Fäden & threads & \\
\hline Garten & Gärten & gardens & lf \\
\hline Vater & Väter & fathers & hf \\
\hline Vogel & Vögel & birds & hf \\
\hline
\end{tabular}

Laaha et al. [2] from elicitation tasks, and Szagun's [15] findings for spontaneous speech, where a slow growth rate was observed for this plural type. The difficulty with pure umlaut forms may reflect the low degree of iconicity in these plural forms since no material is added to express the morphological category. It is noteworthy that pure umlaut forms are particularly difficult to master, whereas plurals with a suffix plus umlaut are mastered more easily. Thus, it is not the vowel change per se that poses difficulty, but the realization of umlaut in the absence of a suffix. In German, application of an umlaut mostly occurs in combination with a suffix, for example, in diminutive forms of nouns (like Apfel-Äpfelchen, "apple-dim") or in comparative or superlative forms of adjectives like (klugklüger-am klügsten "smart-smarter-smartest"). In plural formation, however, umlaut without a suffix does sometimes occur, but only in contexts where the noun stem already contains a pseudosuffix (schwa syllable). It is likely that this special feature of German morphology is critical.

In some aspects, the developmental course of children with SLI was similar to that of the controls: suffixes that were easily mastered in typically developing children (e.g., -n after schwa) also obtained the highest scores in SLI. The most difficult plural form for unimpaired children, the pure umlaut, was also extremely difficult for children with SLI. So far, our data are in line with Oetting and Rice [28] who state that the plural system of preschool children with SLI is constructed in a manner that is similar to that of normally developing children with equivalent language abilities. However, our results point to subtle differences in the hierarchy of difficulty. First, -s plurals turned out to be more error prone for children with SLI than for unimpaired children. The fact that the plural suffix -s is very infrequent in German might explain the difficulty with this suffix. Probably, children with SLI depend more on input frequency than normally developing children, that is, they need more opportunities to hear certain suffixes in the input in order to acquire the form. Second, children with SLI produced twice as many errors in the context of -e plurals than the control groups. The greater problems with -e compared to -(e)n might result from the lower frequency of the ending e within the German plural system [12]. Future research is needed to clarify why -e seems to be vulnerable in languageimpaired populations.

4.3. Error Types. When typically developing children produced errors, different types of errors were observed: substitutions, additions, partial markings, and no markings. The proportion of these error types appeared to be rather stable in typical development except for a decrease of partial markings and a slight increase of "no markings." Both error types reflect the specific problems in the umlaut condition. Partial markings occurred when a plural form requires a suffix plus the umlaut. In all of these cases the umlaut was omitted. The proportion of "no markings" increased, because the predominant error type of the older children was the omission of the umlaut in pure umlaut plurals.

The error analyses of study 2 revealed that children with SLI applied different types of errors than typically developing children. Children with SLI produced a lower proportion of substitutions, more "no marking" errors and more partial markings than their age-matched peers. This tendency to avoid overt plural marking has been reported in other 
studies, for example, in Bartke [7]. It is noteworthy that, in contrast to age-matched peers, children with SLI produced many real suffix omissions in their "no marking errors" and not only omissions of the umlaut in pure umlaut items. This error type indicates that children with SLI may not have fully acquired the iconic relationship between "more referents of a kind" and "more phonological structure" yet.

4.4. Overapplication Patterns. The typically developing children's overapplication patterns in the present study reflects the regularities in the plural system. In line with our hypotheses, -s was mostly used when a suffix was added. Additions mainly occurred in the context of pseudosuffixes (-el, -en, -er, e.g., *Engels instead of Engel- $\varnothing$, "angels"), when no plural suffix is required. These additions can be interpreted as an attempt to overtly mark the function PLURAL. The addition of $-\mathrm{s}$ is also prosodically plausible in these cases since the use of suffixes like -e, -en, or -er would result in a dispreferred sequence of two adjacent schwa syllables (*Éngele). In fact, dispreferred sequences like this did never occur (see prosodic analysis).

As regards substitutions, typically developing children as expected predominantly used the suffix -e. This finding lends support to elicitation studies on German plural formation (see Figure 2) that have shown that overregularizations of -e are frequently used by preschool children. This pattern demonstrates that children rely on unmarked or typical suffixes. For example, the production of *Bäre (regular type (1a), see Table 1) instead of Bären "bears" (marked type (3a)) can be interpreted as a regularization. Moreover, -e is the simplest way to fulfill the prosodic requirement for plural forms (see above). In sum, children's addition and substitution errors indicate sensitivity to the underlying regularities of the morphological paradigm and to the prosodic constraint.

Beyond the similarities in the developmental course of plural acquisition, the present data also point to some qualitative differences between typically developing and SLI children with respect to the suffixes used in overapplications. In particular, children with SLI preferred the addition of -(e)n, while both groups of normally developing children mostly added -s. Within their substitutions, children with SLI tended to choose -(e)n more often than both control groups, while unimpaired children preferred -e. This pattern corresponds to the findings of Schöler and Kany [27], Veit [26], and of Bartke [7]. Penke and Krause [42] consider the use of $-n$ instead of -e (especially in nonfeminine contexts) to be an over-irregularization. The preference for - $n$ turned out to be especially pronounced in two of our single cases. Bartke [7] reported a similar strong reliance on -(e)n for one of her three subjects. Why do at least some children with SLI rely on -(e)n more than children with typical language acquisition? First, the data do not seem to support the strong notion of a deviant pathway of language acquisition in SLI, since the errors observed in the productions of the children with SLI (i.e., the use of -(e)n in overapplications) can be seen in the typically developing children as well; the difference between the groups becomes manifest in the relative frequency of the preferred suffixes. Since deviance implies "something out of the ordinary" [32], we did not find evidence for deviant or extremely unusual structures. Rather, a stronger reliance on frequency may account for the group differences in the overapplication patterns. Since -(e)n has the highest frequency in the target language as well as in child directed speech [12], children with SLI may have applied the suffix that is most salient to them (see also [7]). This interpretation is confirmed by the fact that children with SLI show difficulties with the infrequent marker -s. Given that repeated exposures function as multiple learning trials, the frequent suffix -(e)n is highly accessible for children with SLI, while infrequent suffixes like -s or -e are not salient enough to be easily acquired by language-impaired children.

A tentative interpretation of the differential error patterns in normal and impaired plural acquisition found in our data states that typically developing children show a tendency to meet the prosodic constraint for German noun plurals. In order to produce a trochee with an unstressed final syllable, they choose the most unmarked way by adding a final schwa (-e). Later, they successively acquire the appropriate suffixes of their target language. In contrast, when children with SLI have realized that plural has to be indicated by a suffix, they apply the most frequent one [28].

4.5. Prosodic Analysis. Finally, we investigated whether prosodic constraints on plural formation develop with age or are vulnerable in children with SLI leading to more prosodic violations in younger children or in the SLI group. In both studies, it was shown that violations of the prosodic requirement holding for typical German plural forms are very rare. If those forms occur at all, they consist of a monosyllabic stem with a nonsyllabic suffix (e.g., Bärs instead of Bären, "bears"). Note that such forms are not completely ill-formed as they may occur in -s plurals (e.g., Tipps, "hints," Schecks, "cheques"). Nevertheless, most of the German plural forms obey this constraint, and also the children's plural forms rely on this requirement in over $97 \%$. Even in children with SLI prosodic constraints do not seem to be especially vulnerable although children with SLI may be less sensitive to prosodic information encoded in language.

In summary, a crucial contribution to the investigation of the developmental course of the German plural system was to tear apart overapplication patterns in addition and substitution errors showing that the prosodic shape of the word stem is a decisive factor for the suffix selection: -s was mainly attached to trochaic forms in zero plurals, whereas -e was applied to monosyllabic stem forms. The diverging findings reported in previous studies may be ascribed to this kind of stem characteristics. The second important finding is that the performance of children with SLI not only emerges at the level of MLU-matched children, but also differs in certain aspects from both control groups. In particular, the overapplication patterns found for a subgroup of children with SLI suggest that plural marking in SLI may be guided by other factors than in typical acquisition of morphological paradigms. A high dependency on suffix frequency may be one explanatory factor. 


\section{Conclusion}

The present study contributes to existing knowledge about plural acquisition in German. The results show that the acquisition of the plural system takes quite a long time in German as some parts of the system remain difficult due to the underlying morphological complexity and the combination of rule-based and lexicalized learning. Full mastery of the system is not achieved by age 6 yet. An outstanding difficulty emerges with one plural form (pure umlaut) that requires a vowel change within the word but no overt suffix.

Furthermore, this is the first German study that systematically compared abilities of children with SLI with two appropriate control groups (matched for age and MLU). Our findings revealed some similarities between unimpaired and impaired acquisition, as well as some characteristics of impaired plural acquisition. Plural morphology is a domain where the linguistic problems of children with SLI become evident since they were clearly delayed. Given that children with SLI performed at the level of MLU-matched peers, their limitations with plural formation do not represent an outstanding problem, but are in line with their general lag. Moreover, it turned out that children with SLI, like their typically developing peers, were faithful to prosodic constraints on plural production. Beyond the fact that plural formation abilities are not age appropriate in SLI, the results of the present study indicate that children with SLI show specific differences: first, they were more prone to errors on the infrequent suffix $-s$ than typically developing children. Second, they were less inclined to use -s and -e, but more inclined to overapply the frequent suffix -(e)n. These findings point to a higher dependency on input frequency in SLI.

\section{Acknowledgments}

The authors are grateful to Richard Wiese for the helpful comments on the paper. They thank Stefanie Dädelow, Christiane Simon, Juliane Schwartz, and Ina Kruschke for their help with data collection, Julia Siegmüller and Antje Skerra for their assistance during test construction, Conny Nutsch and Anne Weber for assistance with data coding, and Paula Orzechowska for her assistance with the English.

\section{References}

[1] M. Penke and M. Krause, "German noun plurals: a challenge to the dual-mechanism model," Brain and Language, vol. 81, no. 1-3, pp. 303-311, 2002.

[2] S. Laaha, D. Ravid, K. Korecky-Kröll, G. Laaha, and W. U. Dressler, "Early noun plurals in German: regularity, productivity or default?" Journal of Child Language, vol. 33, no. 2, pp. 271-302, 2006.

[3] P. Eisenberg, Grundriss der Deutschen Grammatik. Das Wort, Metzler, Stuttgart, Germany, 2004.

[4] H. Wegener, Die Nominalflexion des Deutschen: Verstanden als Lerngegenstand, Niemeyer, Tübingen, Germany, 1995.

[5] H. Wegener, "Die pluralbildung im Deutschen. Ein versuch im rahmen der optimalitätstheorie," Linguistik Online, vol. 4, pp. $1-55,1999$.
[6] R. Wiese, "The grammar and typology of plural noun inflection in varieties of German," Journal of Comparative Germanic Linguistics, vol. 12, no. 2, pp. 137-173, 2009.

[7] S. Bartke, Experimentelle Studien zu Flexion und Wortbildung: Pluralmorphologie und Lexikalische Komposition im Unauffälligen Spracherwerb und Dysgrammatismus, Niemeyer, Tübingen, Germany, 1998.

[8] H. Clahsen, M. Rothweiler, and A. Woest, "Lexikalische ebenen und morphologische entwicklung: eine untersuchung zum erwerb des deutschen pluralsystems im rahmen der lexikalischen morphologie," Linguistische Berichte, vol. 3, pp. 105-126, 1990.

[9] H. Clahsen, M. Rothweiler, A. Woest, and G. F. Marcus, "Regular and irregular inflection in the acquisition of German noun plurals," Cognition, vol. 45, no. 3, pp. 225-255, 1992.

[10] I. Sonnenstuhl-Henning, Deutsche Plurale im Mentalen Lexikon. Experimentelle Untersuchungen zum Verhältnis von Speicherung und Dekomposition, Niemeyer, Tübingen, Germany, 2003.

[11] J. Mugdan, Flexionsmorphologie und Psycholinguistik, Narr, Tübingen, Germany, 1977.

[12] S. Niedeggen-Bartke, "Flexion und wortbildung im spracherwerb," in Das Lexikon im Spracherwerb, J. Meibauer and M. Rothweiler, Eds., pp. 208-228, Francke, Tübingen, Germany, 1999.

[13] W. U. Dressler, "Naturalness," in Morphology: An International Handbook on Inflection and Word-Formation-I, G. Booij, C. Lehmann, and J. Mugdan, Eds., pp. 288-296, De Gruyter, Berlin, Germany, 2000.

[14] R. Wiese, The Phonology of German, Oxford University Press, Oxford, UK, 1996.

[15] G. Szagun, "Learning different regularities: the acquisition of noun plurals by German-speaking children," First Language, vol. 21, no. 62, pp. 109-141, 2001.

[16] D. Bittner, "Sprachwandel durch spracherwerb?pluralerwerb," in Angemessene Strukturen. Systemorganisation in Phonologie, Morphologie und Syntax, A. Bittner, D. Bittner, and K.-M. Köpcke, Eds., pp. 123-140, Olms, Hildesheim, Germany, 2000.

[17] I. Gawlitzek-Maiwald, "How do children cope with variation in the input? The case of german plurals and compounding," in How Tolerant is Universal Grammar? R. Tracy and E. Lattey, Eds., vol. 309 of Linguistische Berichte, pp. 225-266, 1994.

[18] K. M. Köpcke, "The acquisition of plural marking in English and German revisited: schemata versus rules," Journal of Child Language, vol. 25, no. 2, pp. 293-319, 1998.

[19] T. Park, "Plurals in child speech," Journal of Child Language, vol. 5, pp. 237-250, 1978.

[20] J. A. Zapf and L. B. Smith, "When do children generalize the plural to novel nouns?" First Language, vol. 27, no. 1, pp. 5373, 2007.

[21] C. Schaner-Wolles, "Plural- vs. komparativerwerb im Deutschen: von der diskrepanz zwischen konzeptueller und morphologischer entwicklung," in Experimentelle Studien zur Flexionsmorphologie, H. Günther, Ed., pp. 155-186, Buske, Hamburg, Germany, 1988.

[22] B. MacWhinney, "The acquisition of morphophonology," in Monographs of the Society for Research in Child Development, vol. $43,1978$.

[23] B. Spreng, "Error patterns in the acquisition of German plural morphology: evidence for the relevance of grammatical gender as a cue," Toronto Working Papers in Linguistics, vol. 23, pp. 147-172, 2004. 
[24] H. Ewers, "Schemata im mentalen lexikon: empirische untersuchungen zum erwerb der deutschen pluralbildung," in Das Lexikon im Spracherwerb, J. Meibauer and M. Rothweiler, Eds., pp. 106-125, Francke, Tübingen, Germany, 1999.

[25] H. Clahsen, "Linguistic perspectives on specific language impairment," in Handbook of Child Language Acquisition, W. Ritchie and T. K. Bhatia, Eds., pp. 675-704, Academic Press, San Diego, Calif, USA, 1999.

[26] S. Veit, "Das verständnis von plural- und Komparativformen bei (entwicklungs) dysgrammatischen kindern im vorschulalter," in Sprechwissenschaft und Psycholinguistik, G. Kegel, Ed., pp. 217-286, Opladen, Germany, 1986.

[27] H. Schöler and W. Kany, "Lernprozesse beim erwerb von flexionsmorphemen: ein vergleich sprachbehinderter mit sprachunauffälligen kindern am beispiel der pluralmarkierung," in Sprechwissenschaft und Psycholinguistik, G. Kegel, Ed., pp. 123-175, Opladen, Germany, 1989.

[28] J. B. Oetting and M. L. Rice, "Plural acquisition in children with specific language impairment," Journal of Speech and Hearing Research, vol. 36, no. 6, pp. 1236-1248, 1993.

[29] J. Niemi, "Production of grammatical number in specific language impairment: an elicitation experiment on Finnish," Brain and Language, vol. 68, no. 1-2, pp. 262-267, 1999.

[30] S. Gray, "Word-learning by preschoolers with specific language impairment: what predicts success?" Journal of Speech, Language, and Hearing Research, vol. 46, no. 1, pp. 56-67, 2003.

[31] E. Hoff and L. Naigles, "How children use input to acquire a lexicon," Child Development, vol. 73, no. 2, pp. 418-433, 2002.

[32] L. B. Leonard, Children with Specific Language Impairment, MIT Press, Cambridge, Mass, USA, 1998.

[33] M. L. Rice, "Grammatical symptoms of specific language impairment," in Speech and Language Impairments in Young Children: Causes, Characteristics, Intervention and Outcome, D. V. M. Bishop and L. B. Leonard, Eds., pp. 17-34, Philadelphia, Pa, USA, Taylor \& Francis, 2000.

[34] V. Stojanovik and J. E. Setter, "Conditions in which prosodic impairments occur," International Journal of Speech-Language Pathology, vol. 11, no. 4, pp. 293-297, 2009.

[35] B. MacWhinney, The CHILDES Database, Discovery Systems, Dublin, Ohio, USA, 1995.

[36] B. MacWhinney, The CHILDES Project: Tools for Analyzing Talk, Lawrence Erlbaum, Hillsdale, NJ, USA, 1995.

[37] C. Kauschke and J. Siegmüller, Patholinguistische Diagnostik bei Sprachentwicklungsstörungen, Elsevier, München, USA, 2009.

[38] R. H. Baayen, R. Piepenbrock, and L. Gulikers, The CELEX Lexical Database (CD-ROM), University of Pennsylvania, Philadelphia, Pa, USA, 1995.

[39] J. R. Crawford and P. H. Garthwaite, "Comparison of a single case to a control or normative sample in neuropsychology: development of a Bayesian approach," Cognitive Neuropsychology, vol. 24, no. 4, pp. 343-372, 2007.

[40] J. Niemi, "Paradigm competition in inflection: an experimental note on Finnish verbs," SKY Journal of Linguistics, vol. 19, pp. 227-235, 2006.

[41] D. Ravid and L. Hayek, "Learning about different ways of expressing number in the development of Palestinian arabic," First Language, vol. 23, no. 1, pp. 41-63, 2003.

[42] M. Penke and M. Krause, "Regular and irregular inflectional morphology in German Williams syndrome," in Williams Syndrome across Languages, S. Bartke and J. Siegmüller, Eds., pp. 245-270, John Benjamins, Philadelphia, Pa, USA, 2004.
[43] H. Behrens, "How to learn a minority default: the acquisition of the German -s plural," 2001, Ms. 


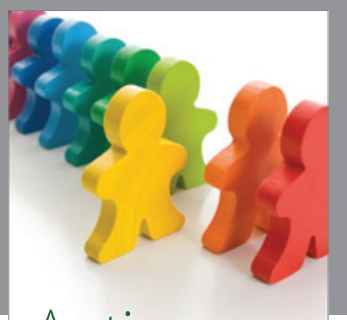

Autism

Research and Treatment
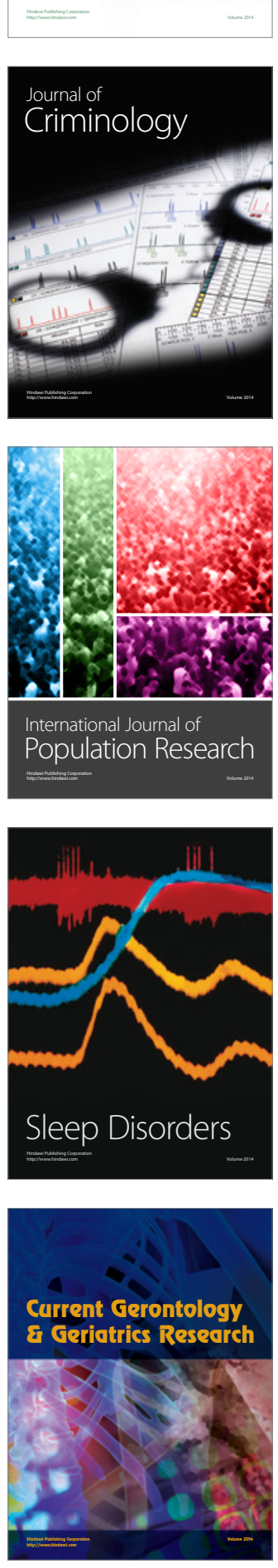
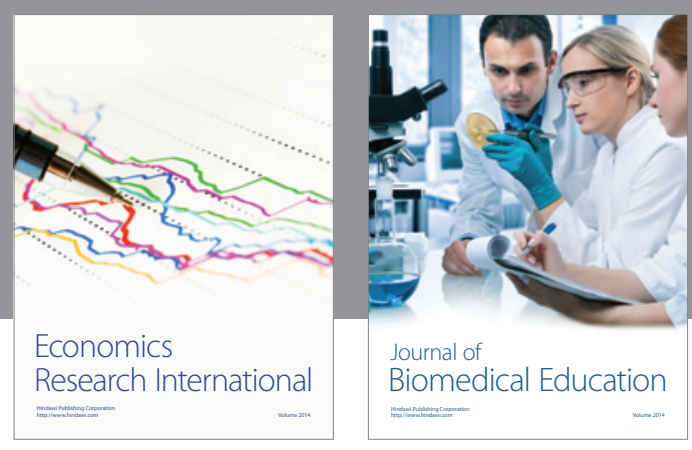

Journal of

Biomedical Education

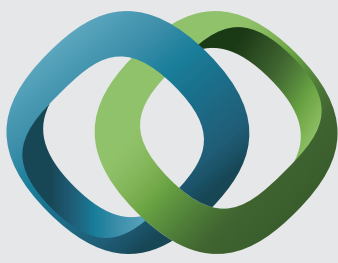

\section{Hindawi}

Submit your manuscripts at

http://www.hindawi.com
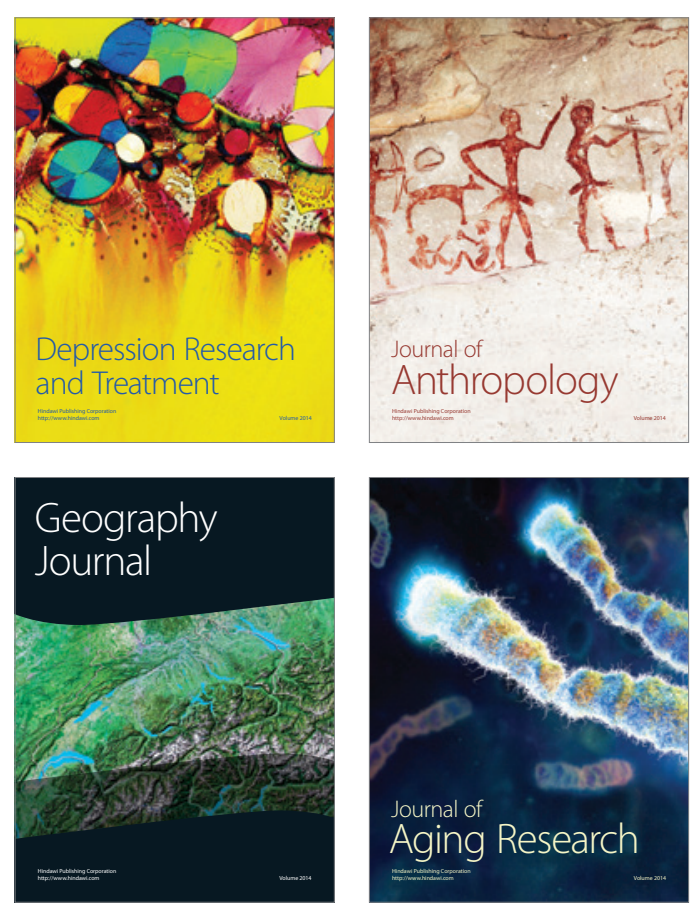

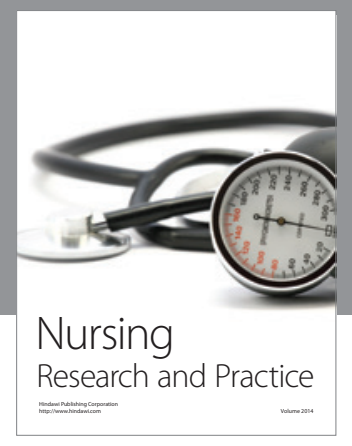

Nursing

Research and Practice

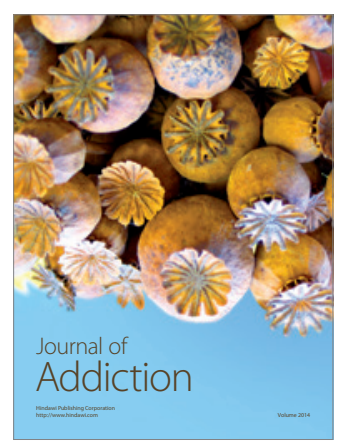

Child Development

Research

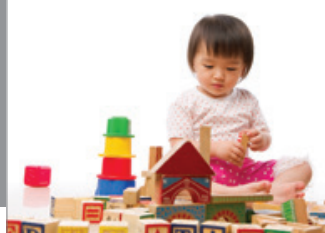

迥
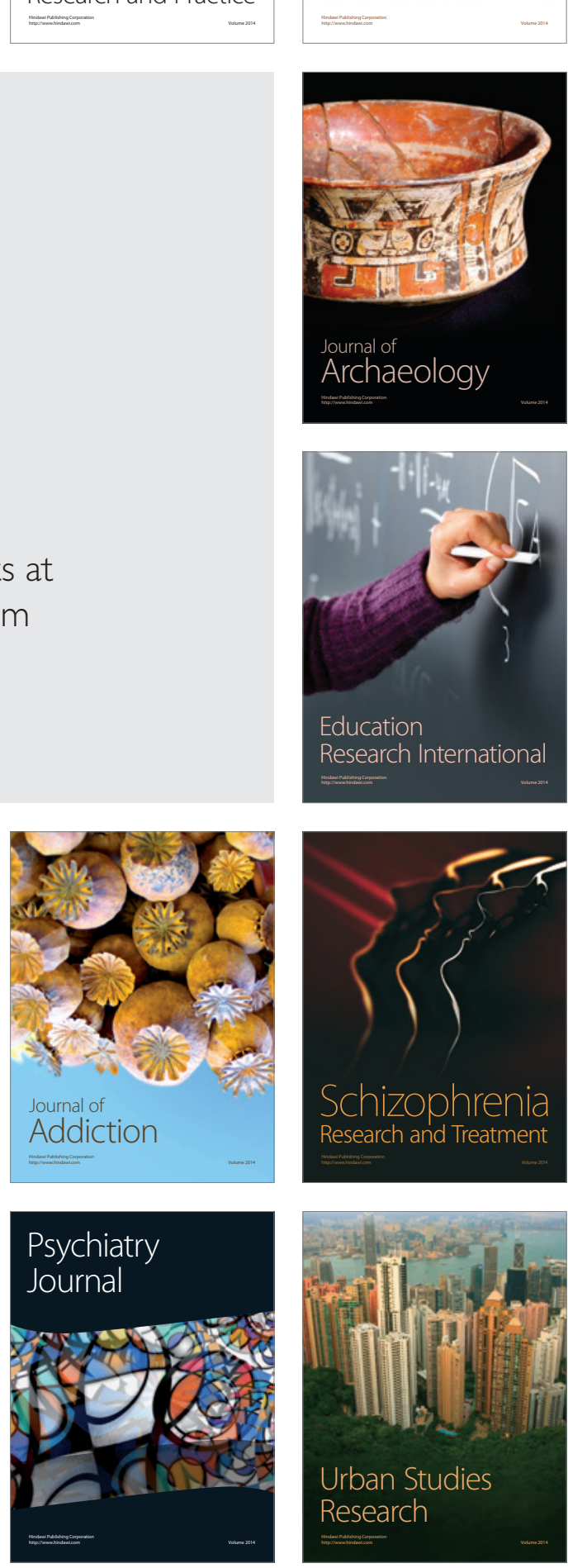